\title{
Targeted Treatments for Restenosis and Vein Graft Disease
}

\author{
Anita C. Thomas \\ Bristol Heart Institute, University of Bristol, 7th Floor, Queens Building, Bristol Royal Infirmary, Bristol BS2 8HW, UK \\ Correspondence should be addressed to Anita C. Thomas, a.thomas@bristol.ac.uk
}

Received 30 September 2012; Accepted 4 November 2012

Academic Editors: C. Hermenegildo, A. Paolicchi, and B. Tesfamariam

Copyright () 2012 Anita C. Thomas. This is an open access article distributed under the Creative Commons Attribution License, which permits unrestricted use, distribution, and reproduction in any medium, provided the original work is properly cited.

\begin{abstract}
Surgery to restore blood flow in arteries blocked by atherosclerotic plaque is a common treatment in cardiovascular disease. Longterm complications of surgical treatment are vein graft disease and restenosis, a renarrowing of the blood vessel after bypass or removal of the culprit atherosclerotic plaque. Attempts to prevent or treat these complications by systemic pharmacological approaches have been largely unsuccessful in the clinic. This has led to an interest in developing targeted or locally delivered strategies. This paper discusses many of the various site-delivered therapies that are under examination as potential antirestenotic and antivein graft disease agents (including antithrombotic, antiproliferative, and anti-inflammatory agents) and why many therapies developed in animal models fail in clinical trials. Techniques of targeted delivery (including stents, "magic bullets," and adventitial delivery) and delivery systems (including nanoparticles and the use of gene therapy) are also discussed.
\end{abstract}

\section{Introduction}

Cardiovascular disease is the leading cause of death and disease globally, with over 17 million people dying of cardiovascular disease each year. Seventy-five percent of these deaths are due to acute events, such as myocardial infarction or stroke, which are commonly caused by blockage of culprit arteries by atherosclerotic plaques [1].

While pharmacological treatments are used to control vascular disease progression or symptoms in patients with mild disease, surgery may be required in more severe or acute cases $[2,3]$. Surgical therapies to treat atherosclerosis target the stenosing atherosclerotic lesion, to restore the flow of blood to downstream organs and tissues. These surgical treatments include arterial bypass grafting (coronary and peripheral bypass grafting), endarterectomy, and angioplasty (with or without stent placement). Although these procedures have improved both patient mortality and quality of life, their success is limited by immediate occlusive complications in up to $18 \%$ of patients, and by the longer-term complications of vein graft disease (vein graft thickening) or restenosis (arterial reblockage at the same site), often resulting in partial or complete closure of surgically treated vessels by 10 years after the procedure $[2,4-8]$.
Neointimal formation is central to both vein graft failure and restenosis [9-12], and also contributes to blockages in arteriovenous shunts and transplanted organs. The neointima is predominantly formed of smooth muscle cells (SMCs) and extracellular matrix, but other components, such as inflammatory cells and thrombus remnants, may also be present [13-16]. Many approaches have been explored to prevent neointimal formation and associated pathological sequelae. These strategies include pharmacological (e.g., cytostatic drugs, anti-inflammatory agents), mechanical (sheaths, internal stents), genetic (gene transfer, stem/progenitor cells), and combination therapies (drugeluting stents, antibody-directed treatments, nanoparticlebased platforms) $[10,17,18]$, but the complete therapeutic prevention of neointimal formation is yet to be achieved.

Many agents used systemically have been effective in preventing restenosis or vein graft disease in animal models have not successfully translated into clinical practice for a number of reasons, including lack of patient compliance, deleterious side effects or difficulties in establishing dosing regimens [19-21]. The antirestenotic drug needs to be present at the site of injury both immediately after surgery and for sufficient time after that, to cover the "window of opportunity." If insufficient drug is given, or given too late, 
for a too short time, or intermittently, then restenosis may still occur. Targeted (or local) treatment not only reduces the amount of drug required (compared with systemic administration), it also eliminates the need for repeated dosing and minimises side effects. One form of local treatment is the drug-eluting stent, which has reduced the restenosis rate to less than $10 \%[3,7,22,23]$. However, it is not possible to use stents to treat all atherosclerotic plaques, and there are concerns regarding stent cost and safety. There are also problems when incomplete stent apposition or inflammation occurs, but of more concern are complications due to delayed or incomplete reendothelialization and/or abnormal endothelial function, leading to late stent thrombosis (and delayed mortality) [24, 25]. However, drug-eluting stents are not the only local treatments available; there are alternative, low-cost, targeted delivery systems.

1.1. Management Strategies for Atherosclerosis. Pharmacological treatments adequately control mild disease progression or symptoms in patients with mild disease [2]. When the coronary or peripheral arteries are extensively damaged or blocked for long stretches, the blocked area may be bypassed by inserting an alternate conduit for the passage of the blood, the bypass graft. The vessels of first choice for such a procedure are the patient's own arteries. If these are unavailable, then autologous veins (usually saphenous vein) or bioartificial or synthetic grafts may be used. Vascular SMCs can respond to environmental changes, by changing from a contractile phenotype to a synthetic phenotype, with more organelles associated with synthesis and proliferation $[26,27]$ and increased production of proteases (such as heparanase, matrix metalloproteinases, and cathepsins) to remodel their surrounding extracellular matrix [28-30]. Vein preparation prior to implantation results in a basal cell death rate of $3 \%$, with more "synthetic" SMC and an increase in degradative enzymic activity $[28,30]$. Gross damage in the vein also occurs once the graft is suddenly exposed to arterial (high-pressure) flow. The endothelium is sloughed away and individual cells are damaged. Underlying SMCs accumulate fluid, and matrix proteins in the adventitia are fractured and the vasa vasorum (if any remains) thromboses [31]. Reperfusion injury factors (such as superoxide radical formation) are observed $[32,33]$, so that the vein shows the influence of both preimplant injury and the new highpressure environment.

While open surgery, such as bypass grafting, remains popular, this technique has several difficulties: (a) the patient is exposed to general anaesthesia and all the problems associated with that procedure; (b) the stenosing lesion may be in a position inaccessible to direct surgery; or (c) the stenosing area may consist of multiple or diffuse lesions that cannot easily be removed [34]. Several techniques that do not require the patient to undergo a general anaesthetic have been developed to remove the offending lesion and may indeed be performed in a day clinic. These include crushing the lesion with a dilating balloon, removal of the lesion with rotating knives or burrs, or burning off the lesion with lasers. The treated segment of artery may be kept dilated with meshed "stents" and the patient given antithrombotic/anticoagulant agents to prevent short-medium term thrombotic blockages of the artery after surgery.

Angioplasty, inflating a balloon within a narrowed artery to crush the plaque and open up the lumen, is a widely used and relatively cheap treatment for lower limb ischaemia, angina pectoris, and myocardial infarction $[7,12]$. It can be complicated by acute closure, spasm and elastic recoil ("rebound"), embolism, or thrombosis [4]. Dilating the angioplasty balloon catheter not only crushes the stenosing lesion, but also stretches the adventitia and removes the vessel endothelium, thus allowing rapid platelet and fibrin deposition. By disrupting the arterial intima and media, the plaque's grumous core may be exposed, thus initiating further clotting responses [12]. The increase in luminal area after angioplasty is due to plaque reduction, plaque translocation to distal and proximal areas, and expansion of the total vessel area, while luminal loss is most likely due to late recoil $[12,34]$. Arteries treated by angioplasty catheters have been reported to restenose about $30 \%$ of the time, but may this rise to $60-75 \%$ in the lower limbs of diabetic patients $[5,7,12,35]$.

Atherectomy may be used instead of angioplasty, but is generally used to debulk restenotic stents or other lesions prior to brachytherapy $[14,36,37]$. The directional coronary atherectomy catheter shaves pieces of plaque into a metal cylinder, and is suitable for removing eccentric lesions [4]. Immediate lumen enlargement after atherectomy is due to plaque removal, not vessel enlargement [38], and there is a restenosis rate of $16-31 \%$ [36].

Brachytherapy (localised ionising radiation) has been used to reduce vascular lesion formation after bypass grafting, balloon injury/angioplasty, and stenting [12, 37, 39]. Its success may result from either reducing the number of proliferating cells (by increasing the number of cells undergoing apoptosis), or by reducing fibrosis and preventing negative remodelling $[3,12,40]$. Treated vessels are known to have incomplete healing, due to a lack of endothelial coverage, persistent fibrin deposition, and inflammatory cell infiltration $[12,18]$.

Lasers debulk the vein graft or artery wall without distortion. Hot-tip lasers (such as the argon laser probe) achieve tissue ablation by thermal effects and can burn through occlusive plaques, but they also result in extensive thermal tissue damage, vasospasm, and thrombus. Cold pulse lasers disrupt chemical bonds by using short, high-intensity bursts of light which promote coagulation and thermal degradation of the vessel wall [41]. The holmium laser has been found to be more effective in treating thrombus-containing lesions than the excimer laser, while the latter may play a role in treating in-stent restenosis or stenosed vein grafts [42-44].

Stents are meshed scaffolds that are inserted into the lumen of the vessel after removal of the plaque by other methods (usually angioplasty). Some stents, however, are placed around the outside of the graft, as an external, supporting sheath $[17,45]$. Lesions treated with internal stents have a reduced incidence of restenosis (compared with angioplasty alone) in large arteries with short lesions $[46,47]$, but require a longer hospital stay with the possibility 


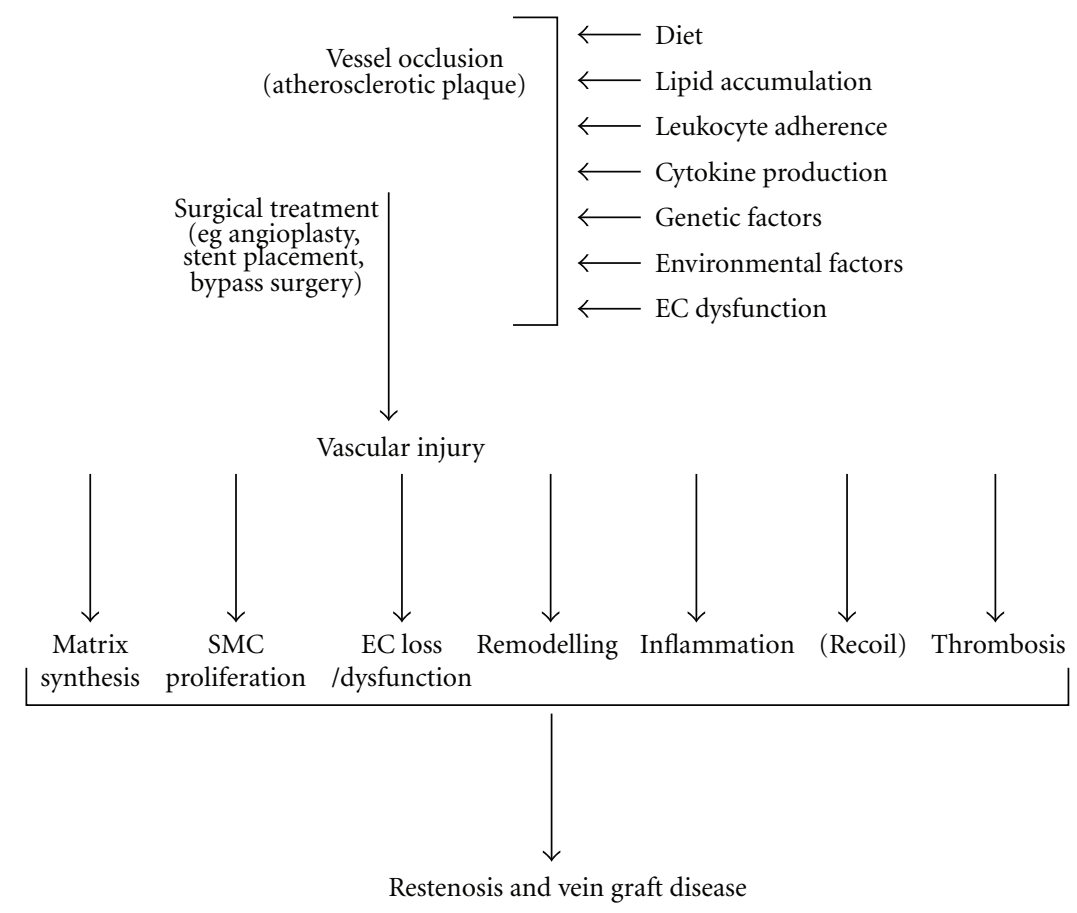

FIGURE 1: Causes and contributors to atherosclerosis, restenosis, and vein graft disease. Surgical treatment in arteries blocked by atherosclerotic plaque may result in restenosis or vein graft disease, caused by endothelial cell (EC) loss or dysfunction, neointimal formation (smooth muscle cell (SMC) proliferation and extracellular matrix synthesis), inflammation, thrombus incorporation into the vessel wall, and vascular remodelling (recoil, medial, and/or adventitial growth).

of more vascular complications that may not be amenable to emergency surgical correction $[46,48]$. As fibrin deposition often occurs on stents $[12,49,50]$, their use requires longterm antithrombotic therapies. Restenosis in stented vessels is associated with the use of multiple stents, degree of occlusion, degree of thrombosis, type of stent, polymer type and composition, excessive stent length, long stenosis length, and the health of the patient [51]. Up to $60 \%$ of patients develop restenosis after stenting, with diabetic patients having the higher rates [5]. Restenosis may occur as a diffuse neointimal hyperplasia, as discrete lesions within the body of the stent or as margin restenosis (possibly due to displacement of the plaque distally and proximally) $[49,52]$. The arteries which develop restenosis may not be treatable by standard surgical therapy [48], but some may respond to in-stent treatment using lasers, angioplasty, or brachytherapy $[12,53]$. This is not always a successful angioplasty to treat in-stent restenosis results in repeat restenosis in 50\% of cases $[12,54]$.

1.2. What Are Restenosis and Vein Graft Disease? Restenosis is an exaggerated response of apparently normal arteries to the typical acute response to injury and is considered the "Achilles heel" of surgical treatment for atherosclerosis. The blockages caused by restenosis and vein graft disease continue to develop with time and are due to a number of processes including intimal hyperplasia (neointimal formation), recoil, vessel remodelling, persistent inflammation, fibrin deposition, and/or thrombotic occlusion (Figure 1).
Neointimal formation (SMC proliferation, migration, and matrix synthesis) in restenotic lesions forms faster than in the atherosclerotic plaque and is a direct result of the surgical unblocking of the artery $[55,56]$, with the degree of vascular injury at least partly determining the occurrence or the rate of growth of the blockage $[13,57]$. Neointimal proliferation is not always present in restenotic lesions, although matrix synthesis usually occurs $[16,18,58]$. When present, the overall proliferation rate is $<4 \%$, although focal hotspots of proliferating cells may occur $[16,55,59]$. The collagenous matrix in restenotic plaques is not well organised and is less compact than in primary plaque. It is enriched in the proteins biglycan, perlecan, hyaluronan, and versican $[16,58,60,61]$. Many of the cells in the restenotic lesions resemble myofibroblasts or "synthetic-state" SMC [62, 63]. There are also macrophages present $[11,16]$, and their existence in large numbers is strongly associated with the development of restenosis [14].

Endothelial cell removal or damage during the procedure exposes the arterial matrix to blood components, triggering platelet adherence and aggregation, fibrin formation and thrombosis $[13,15]$, and influencing the degree of restenosis experienced [9]. As angioplasty and other surgical treatments always result in some degree of endothelial cell loss and thrombosis, reducing the area of mural thrombus may play a role in minimising restenosis or vein graft disease $[6,9]$. It is now evident that patients with luminal thrombus prior to angioplasty or stenting have a higher risk of restenosis than those without thrombus $[64,65]$. The thrombus 
acts as a scaffold and a reservoir of factors produced by platelets, macrophages and even the enzymes of the coagulation cascade. These factors promote SMC migration, proliferation, and matrix production. This, in combination with remodelling mediated by adventitial fibroblasts, leads to restenosis.

Blockages may also be caused by constrictive remodelling $[12,66,67]$. This restructuring of the artery or vein graft relies on the action of matrix proteases to breakdown the extracellular matrix [28, 68-70], and this in turn is influenced by changes in blood flow $[66,67]$. Restenosis can occur when the remodelling reduces the vessel diameter, when remodelling does not occur, or when the amount of expansive remodelling is insufficient to compensate for lesion development [66]. Animal models of stenosis have shown that both vascular remodelling and neointimal hyperplasia determine the final luminal area $[57,71,72]$. The use of stents reduces the contribution of recoil and remodelling to restenosis, but appears to increase the contributions of inflammation and thrombosis.

While it would be convenient to define treated vessels as "restenotic" or "nonrestenotic" (or with or without vein graft disease), the response to surgical treatment is not "all or nothing," but varies over the entire spectrum [12]. There are a number of techniques designed to detect the degree of vessel narrowing after treatment (with varying degrees of accuracy), but another problem in comparing antirestenotic treatments lies in the timing of detection and ambiguity in the definition of restenosis. Clinical restenosis is usually measured between 3-12 months after treatment, although some groups have examined arteries as early as 1 month and as late as 29 months after treatment. Restenosis has been characterised as a return to $\geq 70 \%$ stenosis and loss of $\geq 50 \%$ of initial gain; the loss of $\geq 0.7 \mathrm{~mm}$ of the vessel diameter; $\geq 50 \%$ stenosis; loss of $50 \%$ of initial gain; $50-75 \%$ stenosis; \% loss of initial gain; change from $<50 \%$ to $\geq 50 \%$ stenosis; $\geq 50 \%$ stenosis and $>50 \%$ of initial gain or $>20 \%$ luminal diameter; or the recurrence of clinical symptoms or adverse events. Binary stenosis divides the cohort of patients (or blockages) into those with $<50 \%$ stenosis and those with $\geq 50 \%$ stenosis (regardless of initial gain) $[5,8,14,21,22$, $46,53,73-88]$. Vein graft disease is usually measured as $\%$ stenosis. These differences in how, what and when the measurement is taken can make decisions as to the suitability of a treatment, or comparisons between treatments difficult to determine, particularly as restenosis and vein graft disease do not stop developing (after an arbitrary time point).

\section{Treatment Development and Translation}

Many different animal models have been created to investigate treatments to prevent vein graft failure, lack of reendothelialization after surgery, thrombus formation, neointimal formation, restenosis, and vulnerable plaque behaviour. While many therapies have successfully reduced experimental neointimal formation, restenosis, and vein graft disease, they are often less successful when tested clinically. This may be due to the following potential limitations: (a) different endpoints were studied-in animal studies, differences between treatments in neointimal area are usually measured after termination, using histology and morphometry. However, many differences found in animal models would not have been detectable if measured using testing modalities or definitions of restenosis used clinically [9, 12, 20, 89]. Using alternative or multiple endpoints may have prevented less profound or marginal therapies progressing to clinical trials;

(b) interspecies differences-models in rodents (frequently used to model neointimal formation/vein engraftment/vulnerable plaque [90-93]) may be of limited use in predicting the clinical efficacy of a treatment. The use of multiple species may eliminate less appropriate therapies from progressing to the clinic;

(c) differences in the response of an artery to injuryarteries from anatomically different locations in the same animals, arteries of different sizes in the same animal, and arteries of the same size in different species may all have different responses to injury $[10,67,94,95]$. In addition, for convenience and for ethical reasons, some animal models examine the response of easily accessible arteries that may not be a problem clinically;

(d) unsuitable model-animal models, of course, are designed to mimic the target disease in a timely fashion. However, most animal models of restenosis involve the manipulation of arteries that are initially free of atherosclerosis to form a neointimal thickening. These models do not allow for the multiple process that contribute to the initiation and progression of restenosis, vein graft disease, and the atherosclerotic plaque [10] (Figure 1). However, they may model aspects of the diseases. For example, lesions formed in the aortae of rabbits after fat feeding are good model of fatty streak formation (but not of atherosclerotic plaque formation). Similarly, the neointimal thickening that forms after balloon injury of the rat or rabbit carotid artery is a good model of early in-stent stenosis [20,96]. Dogs have hypercoagulable blood [92], and thus provide a good model for testing therapies that limit thrombus formation. A combination of insults or models may be necessary [20,97];

(e) premature end of treatment-many trials of antirestenotic agents, particularly in small animals, end at 2-3 weeks after surgery, while studies in the pig often end at 4 weeks. However, it has been shown that "catch-up" may occur, that is, the neointima continues to develop after that time (as it does clinically) until there is no longer a difference between the agent and the control $[95,98]$. Although it may add to the expense and the "ethical burden" of a study, continuing the experiments for a significantly longer period may a better test of the treatment; 
(f) the wrong response is targeted-in animals, drugs are often tested for their ability to prevent neointimal formation, whereas in clinical trials they are usually tested for their ability to regress established disease. In addition, while much of the restenotic plaque consists of extracellular matrix, many of the antirestenotic treatments are focused on reducing SMC proliferation. Alternative targets may be the extracellular matrix itself, the blood products that are incorporated into the plaque, thrombus formation, inflammation, the endothelium, or preventing SMC phenotypic change or long-term vessel remodelling. Limiting a therapy to only one of these many aspects (such as SMC proliferation) not be effective when observed clinically [18];

(g) reductions in the dose of the agent delivered-doses of drugs found most effective in animal models are often reduced in the clinic, sometimes by as much as 70-fold [99]. This may be due to noncompliance, but it may also be because symptoms that cannot be detected in animals (such as nausea) and alterations in body functions permissible in animal models (such as changes in blood pressure) are not tolerated in humans [99];

(h) the duration of exposure to the agent given clinically may have been outside the window of interventional opportunity established in the animal studies. After an initial critical time point, the events of restenosis occur over an extended time period-probably weeks, possibly months. Thus, the delivery system must be in place and active soon after (or even before) surgery, must be able to deliver the activated form of the chemical of interest for extended periods of time, and must be biologically inert in other ways, so as not cause an adverse reaction either in the vessel of interest or in other tissues [99, 100]. The benefits of several potential antirestenotic agents have been shown to be dependent on their presence in the animal before angioplasty, that is, pretreatment with the drug is necessary to achieve an effect. However, in an acute clinical case pretreatment with an agent is not possible and the drug may be administered after its optimal dosing time [64]. This is particularly important for those drugs disrupting the early steps in neointimal development.

It is very possible that many of the differences in treatment effectiveness observed between animal models and the clinic may be eliminated by a more thorough preclinical examination prior to the therapy being released to clinical trial. However, there are some differences (such as duration, dosing and timing difficulties and side effects) that become apparent only after studying the treatments in clinical trials. One way of preventing the complications of many treatments is to deliver the antirestenotic agents locally rather than systemically. Thus, systemic effects, as well as the incidence of bleeding and restenosis, should all be minimised.

\section{Targeted Delivery Techniques}

To successfully reduce the incidence or degree of restenosis, agents (whether naked or encapsulated, mechanical or drug, gene or cellular) must be available in a usable form at the site of interest. There are many ways in which antirestenotic agents can be locally or site-delivered, including directly via luminal delivery catheters, in gels or microspheres placed around the adventitia, or on coated stents, but some of these techniques may result in greater trauma to the vessel than the potential benefit of therapy [101]. Agents that interact only with certain types of cells (such as rapidly proliferating cells or cells with a particular membrane receptor) or antibodies linked to agents may also be used [102-107]. The locally delivered substances result in increased concentrations of the drug in the place where it is required, leaving the remainder of the body with much lower levels of the drug. Ideally, target delivery of the drug should also extend the residence time of the drug, and may also improve its activity and bioavailability. These combined actions reduce (or eliminate) the need for repeated administration of the drug, reduce side effects (systemic effects and damage to healthy tissue) and maintain a more uniform delivery of the drug. As there is a single dose, the cost and length of time in hospital may be reduced, but there is little opportunity to alter the dose of drug given.

3.1. Stents. When used in the lumen of vessels, stents are used as scaffolds to hold open arteries after plaque removal, preventing spasm and remodelling, and are thus ideal as a local delivery medium. When loaded with antiproliferative compounds (such as paclitaxel or rapamycin) drug-eluting stents have significantly reduced the restenosis rate to less than $10 \%[7,23,108,109]$. However, their use is not totally devoid of problems. Many stents evoke an inflammatory response and are limited as to the amount of agent that can be applied to them. This can lead to eventual drug depletion from the stent $[23,99,110,111]$. Long-term drug treatments (such as antithrombotic treatments) are usually used concurrently with the stents [112]. Despite this, drugeluting stents are associated with an increased incidence of delayed thrombotic events (usually associated with impaired reendothelialization after stent placement and the end of antiplatelet therapy or noncompliance with the therapy), safety issues (e.g., polymer toxicity, bioincompatibility), increased cost, and the unsuitability of stents for certain anatomical locations or conditions $[7,23,50,111]$.

3.2. Delivery Catheters. Delivery catheters, like angioplasty catheters, are inserted into the artery and used to deliver therapies locally into the vessel wall $[23,99,113,114]$. Catheters coated with a gel containing the agent and catheters which inject the agent into the artery wall through fine needles or a fine spray have been trialled [21, 23, 99], but are expensive, may result in vascular barotrauma and are potentially damaging if incorrectly placed $[99,115]$. Another form of delivery catheter, the double-balloon catheter, stops the flow of blood through the vessel under study by inflating balloons at either end of the catheter. The agent is introduced 
into the cavity and allowed to passively infuse into the artery wall. This involves long dwell times resulting in vessel ischaemia and is not suitable for many arteries, including coronary vessels [99, 115]. Most catheters have variable delivery efficiencies, with much of the infused material subject to washout (with subsequent systemic exposure) $[18,99]$.

3.3. Perivascular Delivery. During perivascular delivery, the therapy is deposited around the adventitia of the artery or engrafted vein. The active agent leaches from the delivery vehicle or carrier and diffuses into the vessel wall, aided by the vasa vasorum (if intact), until there is an even distribution of the drug throughout the vessel [116]. Thus, there is an increase in local drug concentration without significant systemic effects [117]. There have been several preclinical studies designed to extend the dwell time around the vessel, including encapsulation of the drug in microspheres, or holding the treatment in place using gels made of fibrin or pluronic material [116, 118-121]. An alternative solution may be to expose the vessel to the cell that makes the treatment, rather than present the drug directly to the vessel $[122,123]$. External stents (or scaffolds) placed around vein grafts may also be used as a form of local drug delivery, restricting the treatment to the adventitial area inside the stent. However, vessels that have been treated transluminally (e.g., angioplasty, internal stent placement) are not suited to perivascular delivery techniques.

3.4. Ex Vivo Delivery to Vein Grafts. Vein grafts lend themselves particularly to treatment ex vivo, with treatment occurring after the vein has been harvested, while the arterial insertion site is being prepared. Luminal or adventitial administration of antithrombotic or antirestenotic products spare the cut edges of the vessel and can be performed without delaying the surgical procedure [124, 125]. Drugs may be administered directly, but gene or cell seeding treatments are becoming more common [40, 124-127].

3.5. Antibody-or Peptide-Targeted Therapies. Targeted delivery of antirestenotic drugs has also been achieved by utilising a technique similar to Nobel Prize winner Paul Ehrlich's "magic bullet" for the treatment of cancer [128]. Drug-linked antibodies are a form of noninvasive treatment that delivers the drug of choice directly to the target tissue. If the antibody is sufficiently specific, only a low concentration of the agent bound to the antibody need be administered. The chance of long-term deleterious effects is very low.

For example, antifibrin antibodies can target clots specifically. After surgical disruption of the atherosclerotic plaque or placement of a vein graft, factors in the artery wall (such as collagen, phospholipid, or the grumous core) are exposed, and provide sites for fibrin formation and the recruitment of more platelets $[103,129]$. This fibrin is deposited onto the injured artery surface within 10 minutes of injury, where it can remain for at least 24 weeks [130]. Antibodies recognising fibrin have been conjugated to a number of potential therapies, to target the drugs to the site of fibrin formation, that is, the site of injury. Various antibody-drug therapies have been shown to reduce thrombosis, neointimal formation and vessel remodelling, as well as improving reendothelialization in the vessel [102, 104-107, 131].

Other treatments targeting the thrombotic system have also been employed to deliver antithrombotic drugs. Arginine-glycine-aspartic (RGD) peptides target the integrin GPIIb-IIIa receptors expressed on activated platelets, and have been used to direct liposome nanoparticles for treatment delivery [132]. Similarly, the surface of perfluorocarbon nanoparticles has been bound to targeting ligands including tissue factor, collagen and integrins [133-135].

Some growth factors and cytokines are selective for certain cell types or for cells under specific conditions. This allows the delivery of toxins or other agents directly to the cell, so that the cell accepts the conjugate and then dies or alters its behaviour. Compounds used include saporin, diphtheria toxin, and pseudomonas toxin linked to fibroblast growth factor (FGF)-2, epidermal growth factor (EGF) or transforming growth factor (TGF)- $\beta[99,112$, 136]. FGF-saporin, for example, limits neointimal formation in injured rat carotid arteries by killing medial SMCs [99]. In another study, adenoviruses (encoding a tissue inhibitor of metalloproteinase) were linked with peptides targeting metalloproteinases (present in increased numbers in restenotic tissue) to limit neointimal thickening in a rabbit model [137].

3.6. Gene and Cell-Based Targeted Delivery. There is considerable interest in the use of gene therapy in the treatment of restenosis and atherosclerosis. One approach is to seed the vasculature with cells containing the gene for a particular product. Alternatively, the gene therapy can occur by directly transforming the cells of the artery wall in situ by infusion of naked DNA or antisense oligonucleotides or by packaging the genetic material into liposomes or viruses $[99,123,125$, $138,139]$. This may be targeted to the area of interest by the use of catheters, microbubbles, gene painting, nanoparticles, or stents to target the lumen or adventitia of the vessel. However, the agent must be capable of moving into the cell, where, if successfully integrated, the product is manufactured and released into the local environment.

Many of the current methods of in vivo gene transfer are subject to high rates of washout and have a short exposure time, poor levels of targeting and low transfection efficiency. The proportion of successful transfers varies. About $1 \%$ of cells take up DNA liposome or virus while there is a transfection rate of $10-70 \%$ through the use of adenoviruses [99, 112, 115]. Gene vector delivered by catheters during angioplasty can have a 5\% transfection efficiency, intramuscular injection a $0.1-1 \%$ efficiency (with adenoviral vectors), and periadventitial delivery a $0.1 \%$ efficiency $[89,140,141]$.

\subsection{The Use of Nanoparticles in Targeted Drug/Gene Delivery.} One way to improve the delivery efficiency of drugs or genes is to enclose or attach them to nanoparticles. Nanoparticles are $1-100 \mathrm{~nm}$ in size, with a large surface area, and often have magnetic and fluorescent properties [131, 134, 135, 142]. After incorporation into nanoparticles, the therapies should 


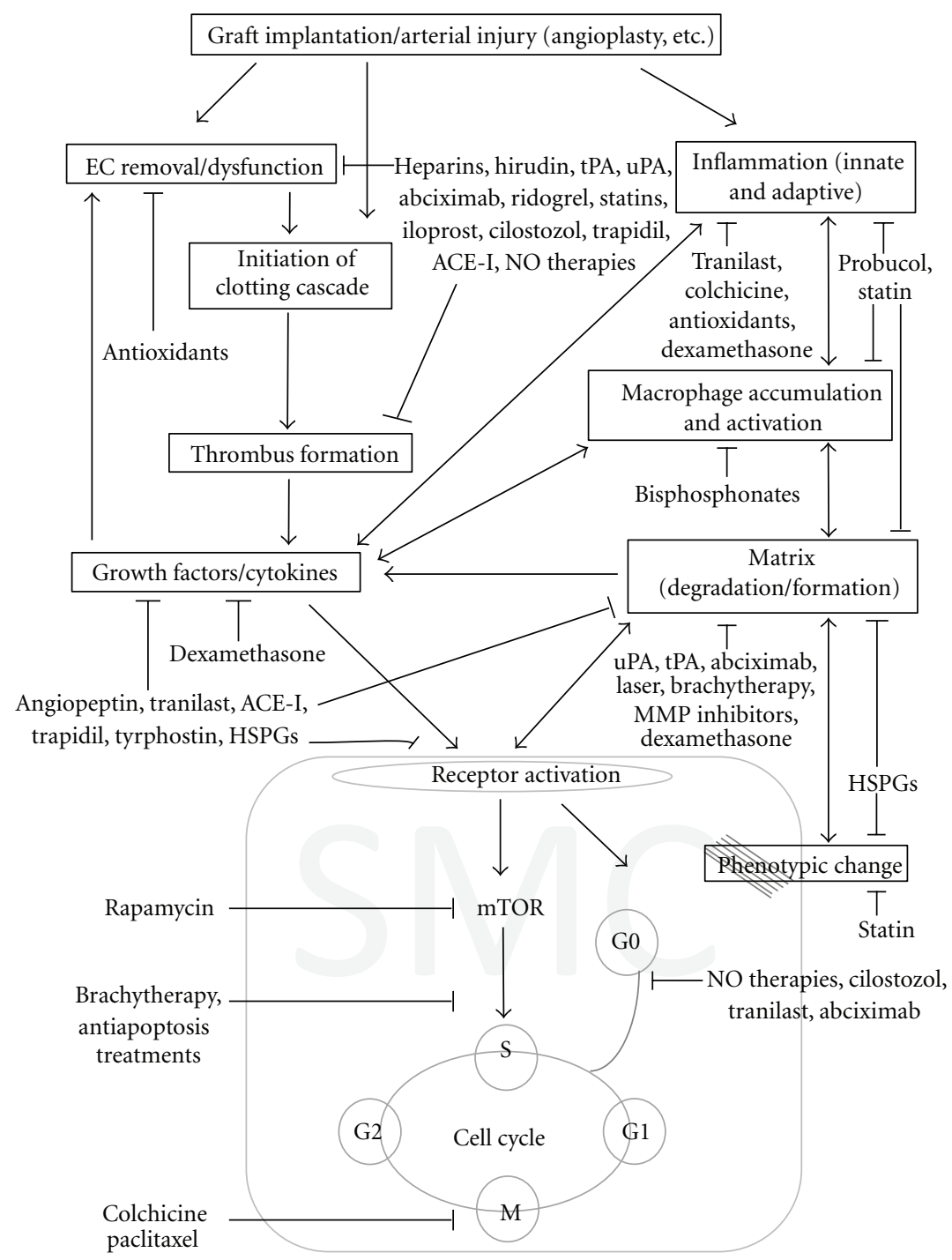

FIGURE 2: Sites of action of antirestenotic drugs. After surgical treatment for atherosclerosis, a number of drugs with antirestenotic potential may be administered to retard or eliminate the development of restenosis or vein graft disease. These include anticoagulants, antiplatelet and antithrombotic drugs, anti-inflammatory agents, antiproliferative and cytostatic drugs, lipid-lowering drugs, and antioxidants. ACEI: angiotensin-converting enzyme inhibitor; HSPG: heparan sulphate proteoglycan; MMP: matrix metalloproteinase; mTOR: mammalian target of rapamycin; NO: nitric oxide; SMC: smooth muscle cell; tPA: tissue plasminogen activator; uPA: urokinase plasminogen activator.

be better protected from degradation, making them available for longer periods and enhancing their therapeutic effects. This is a particular advantage for hydrophilic drugs, which are otherwise readily lost.

A number of different types of nanoparticles have been examined for their potential in antirestenotic therapies. These include organic liposomes, polymers, and perfluorocarbon nanoparticles and inorganic nanoparticles such as layered double hydroxides (LDHs), magnetic nanoparticles, and titanium oxide $\left(\mathrm{TiO}_{2}\right)$. For example, liposomes incorporating antirestenotic drugs have been used to coat metallic stents and shown to function as a drug carrier in small animals [143-145], while LDH has been used to increase the amount of drug delivered in fibrin/antibody-targeted therapy [131].

\section{Targeted Therapies}

Many drugs have been tested in vitro and in animal models for their potential in the prevention or reduction of restenosis and vein graft disease. Most treatments are directed at reducing one or more of acute thrombosis; vessel recoil; remodelling; neointimal formation (including SMC phenotypic change, migration and proliferation, and extracellular matrix formation); inflammation; incomplete reendothelialization; altered endothelial cell behaviour; delayed thrombosis (as outlined in Figure 1).

Antirestenotic drugs and therapies can be categorised into several groups based on their original use and/or targets (Figure 2). These include anticoagulatory, antithrombotic and antiplatelet agents (e.g., heparin, ridogrel); 
anti-inflammatory agents (e.g., dexamethasone, tranilast); antiproliferative drugs and growth factor antagonists (e.g., trapidil, tyrphostin, angiotensin-converting enzyme (ACE) inhibitors); cytostatic drugs (e.g., paclitaxel, rapamycin); lipid-lowering agents (e.g., statins); and antioxidants (e.g., probucol, resveratrol) $[10,18,115,146-151]$.

4.1. Antithrombotic and Antiplatelet Agents. When given after acute events, oral anticoagulants/antithrombotics can reduce the incidence of reinfarction or stroke, and so have become a standard treatment after acute myocardial infarction. Anticoagulants, as antirestenotic agents, may limit the amount of thrombus incorporated into the artery wall, thus minimising bulk in the stenosis and removing a potential source of factors that stimulate SMC migration and proliferation. Some, like the heparins, may also act as a replacement for lost extracellular matrix or act more directly as an antiproliferative agent. Platelets play a significant role in restenosis by releasing agents that may act as potent mitogens of SMC migration and proliferation, and by increasing the degree of thrombus buildup on the artery wall. Thrombin inhibitors act by preventing the formation of thrombin or interfering with thrombin's properties, thus preventing thrombus formation and platelet deposition in, or on, the artery wall.

The anticoagulants heparin and low molecular weight hep$\operatorname{arin}(L M W H)$ inhibit proliferation and migration of arterial SMCs in vitro and in vivo if given immediately after injury at a suitable tissue concentration [19, 117, 118, 152, 153]. Data concerning clinical restenosis rates after heparin treatments have been conflicting, but this may be due to the dose of heparin given in many of these trials being considerably lower than those shown to be effective in animals $[21,75$, 154]. Heparin has a short half-life, and it may be the timing of intervals between heparin doses that are critical in the prevention of restenosis $[19,115]$. Rats given heparin at time intervals comparable to those given in clinical trials had increased hyperplasia after balloon injury compared with those given no heparin. When heparin was given continuously, however, both intimal hyperplasia and intimal proliferation were significantly reduced [19]. Unfortunately, clinical treatment with heparin given systemically can result in bleeding complications at other sites unless low doses are given [155]. To prevent this complication, it is best to administer heparin and related compounds as a single dose, locally delivered therapy.

It is not necessary for heparins to enter the cell to exert their effect. If administered at sufficient concentration and at the correct time, they remain effective in reducing SMC proliferation even when bound to extracellular matrix [115]. This may explain why stents covalently coated with heparin ("Hepamed" Wiktor stents) placed in the pig coronary artery were found to be effective in limiting SMC proliferation and restenosis [153], even though it is unlikely that all of the heparin was released from the polyethylene imine polymer on the stent. This sort of stent will extend the active life of the heparin (for at least 4 months) as well as keeping it local to the tissue being treated [40]. Other researchers, using a similar model, failed to find a difference in neointimal formation between the control (bare metal stent) and the heparin-eluting stents. This is probably because the dose of heparin released from the cellulose ester polymer on the stent was too low to be effective $(<0.001 \mathrm{U} / \mathrm{hr}$ released over the first week) [156]. A stent coated with $3.2 \mathrm{U}$ of ionically bound heparin (which is readily released from the stent so it can be taken up by cells or available to neutralise thrombin [40]) reduced proliferation, thrombus formation and neointimal area in a similar pig model [157]. A clinical trial of the "Hepamed" heparin-eluting stent found that it was effective in reducing thrombotic events [158]. In the Benestent II study, Palmar-Schatz-style heparin-eluting stents were effective in reducing the degree of restenosis and number of clinical events 12 months after the procedure [159], but a trial using the low dose Jostent $(<1 \mathrm{U}$ heparin/stent) was inconclusive [160]. In the successful trials, the restenosis rate was reduced from $31 \%$ to $7-16 \%[159$, $160]$; it would be interesting to ascertain what the rate would be if the treatment was optimised. It is evident that the dose of heparin bound to the stent and the way the heparin is bound to the stent (e.g., noneluting (covalent) or diffusible (ionic)) are critical to the success of treatment with heparin. Unfortunately, it is all too easy to combine the results of these heparin site-delivery studies, label them as "conflicting" and stop research in this area.

While LMWH can inhibit cultured human SMC proliferation by $20-40 \%$ [152], this does not prevent phenotypic change or proliferation of rabbit SMC [119]. Effects in vivo are also variable $[119,161]$, but LMWH at 10 times the clinical dose was able to maintain lumen diameter in rabbit models (arterial injury with or without atherosclerotic diet) by reducing the incidence of early SMC proliferation [161, 162]. Local delivery of LMWH after vascular injury using a porous balloon catheter was associated with improved reendothelialization, and elevated early and reduced late SMC proliferation, resulting in reduced neointimal formation compared with control rabbits $[162,163]$. Clinically, systemic high dose LMWHs (with or without pretreatment) may improve patency in peripheral bypass grafts [39], but may not prevent restenosis [74, 78, 80, 81]. Further clinical studies of locally delivered LMWH pinned in place with a stent after drug administration showed a decreased the degree of restenosis [82], but a study on "unsecured" LMWH delivered in a similar manner found that the drug was not effective [164]. It may be that LMWH needs to be held in place in order to act as an antirestenotic agent.

In order to keep the anticoagulant in position in at the site of surgery (the site of fibrin formation [130]), an antibody that recognises cross-linked fibrin D-dimer was conjugated to heparin or LMWH and these conjugates injected i.v. into rabbits after balloon injury. Animals given either conjugate had reduced neointimal formation, decreased luminal narrowing and positive remodelling, with more endothelial cells and fewer neointimal cells [106]. More recently, LMWH was intercalated into $\mathrm{LDH}$ nanoparticles prior to conjugation to the same antibody, to increase the dose delivered and improve the therapeutic effectiveness of the LMWH [131]. Enclosure within the LDH improved the bioavailability of the LMWH and protected it from 
degradation within the cell, resulting in reduced SMC proliferation and migration $[165,166]$. Conjugating LMWH-LDH to the antibody did not interfere with the antibody's ability to bind to cross-linked fibrin or in the ability of vascular cells to internalise the conjugate. Injured arteries exposed to the nanoparticle conjugate had decreased neointimal formation and increased patency compared with those given control agents [131].

Hirudin prevents thrombin-catalysed activation of coagulation factors, fibrinogen cleavage, and platelet aggregation, thus limiting thrombus formation [167]. It is effective in reducing neointimal area and tissue factor expression in balloon-injured hypercholesterolaemic rabbits [168-170] but has conflicting results in injured pig arteries [15, $167,168,170]$, probably due to differences in dosing and timing regimens. Interestingly, it does not appear to have an effect on cellular proliferation in vivo [169]. In the clinical HELVETICA study, hirudin (given systemically) was found to cause a reduction in early cardiac events, but did not prevent restenosis or improve long-term survival [77]. However, the dosage used in this study was 5-fold less than those used in animal experiments. An antibody-directed fibrin peptide-targeted form of Xa-activated hirudin has been made. This conjugate preferentially targeted clots and activated hirudin at the site of the thrombi. It also prevented thrombus formation on synthetic grafts in primates [103, 129]. Hirudin-coated stents in pig arteries were found to reduce thrombus formation and neointimal area [110], while stents coated with a hirudin-iloprost combination also reduced restenosis in pig and sheep arteries. However, over half of the hirudin was released within the first 24 hours, suggesting that the positive effect was largely due to the presence of iloprost, which eluted slowly from the stent polymer [171].

Elements of the fibrinolytic pathway have been utilised as antithrombotic agents, but their systemic use at therapeutic doses can lead to uncontrolled bleeding or rebound thrombosis $[6,172]$. To eliminate these complications, a number of site-delivered or targeted therapies have been developed. "Synthetic-state" SMCs are known to have impaired tissue plasminogen activator (tPA) production and SMCs from atherosclerotic plaques a reduced capacity for initiating fibrinolysis [173], possibly because of complexing of the enzyme with the increased amounts of plasminogen activator inhibitor (PAI)-1 present in plaque [174]. Vein grafts have an early loss of tPA-associated fibrinolytic activity [175], with failed grafts having less tPA than viable grafts [176]. Targeted delivery of urokinase plasminogen activator (uPA) to arterial thrombi using coated catheters and tPA delivery by a microporous catheter as a bailout intervention for peripheral artery disease and to treat thrombus in coronary arteries have been investigated [23]. Antibody conjugates have also been used to target-deliver tPA to the site of thrombus formation [104]. Luminal exposure of pig vein grafts to tPA enzyme was found to be sufficient to improve the thrombolytic activity of the grafts [126]. In other experiments in pigs, tPA gene therapy was delivered locally to vein grafts ex vivo, to replace the tPA lost from endothelial cells and their underlying SMC in the graft, thus limiting acute thrombus formation following implantation of the graft into pig carotid arteries [125]. Blood flow in the transduced grafts was higher than in control grafts. This is an important observation, as a high initial blood flow in the graft is known to be critical in limiting thrombosis and graft failure [177]. Fewer plateletrich thrombi (measured as cyclic flow reductions (CFRs)) formed in the tPA-transduced grafts, and any CFRs that did form were smaller and resolved faster than those formed in grafts given a control virus [125]. Reduction of the thrombus load in vein grafts should lead to a reduction in neointimal formation and vein graft disease [6], or delay the onset of these pathologies. However, the dose of tPA and the vessel involved are critical, as excess tPA may result in early extracellular matrix degradation and increased neointimal formation [178].

Agents that block the platelet GPIIb/IIIa receptor, the most abundant glycoprotein on the platelet surface, inhibit the binding of fibrinogen to platelets and hence platelet aggregation [179]. These agents include aspirin, ticlopidine, roxifiban, and clopidogrel. When given systemically, they can reduce the incidence of thrombosis in animal models [180], but do not always reduce neointimal formation [181]. When given clinically they reduce the number of cardiac events [182], but trials suggest that they are not effective in reducing restenosis [183]. Cessation of clopidogrel therapy is associated with late stent thrombosis [23]. Systemic administration of abciximab, a manufactured antibody against the GP IIb/IIIa receptor, also reduces clinical events (if maintained for a sufficient time $[184,185])$, but is not associated with improved outcome after stenting or a reduction in restenosis rates [186]. Abciximab does, however, have a positive effect in patients with diabetes [151]. When delivered locally using a spiral delivery catheter, abcximab reduced the thrombotic burden in stenosed vein grafts [187]. This treatment may also be of benefit in the treatment of thrombosed coronary arteries [23]. Preclinical experiments on stent-delivered abciximab in pigs indicated that neointimal formation and inflammation levels after this treatment were comparable to vessels given paclitaxel- or rapamycin-eluting stents (see below) [188].

Thromboxane A2 $\left(\mathrm{TXA}_{2}\right)$ is a potent vasoconstrictor, and is produced by platelets during signal transduction after activation of the platelet receptor GP IIb/IIIa [184]. $\mathrm{TXA}_{2}$ synthetase inhibitors such as ridogrel are effective in preventing platelet aggregation in balloon deendothelialised rabbit arteries [189] and human arteries after angioplasty [190] and reduce the incidence of clinical restenosis [191]. Ridogrel also increases vasodilatation. Combined systemic ridogrel/ketanserin or ridogrel/ketanserin/clopidogrel treatment prevented platelet aggregation (as CFRs) in stenosed or balloon-injured coronary arteries in a dog model and reduced neointimal formation [192, 193]. While ridogrel has been successfully delivered into the artery wall of dogs via a microporous balloon, it resulted in only transient high vessel wall concentrations of the chemical [194] and was found to be ineffective in reducing thrombus and neointimal formation. 
Iloprost is a prostacyclin analog with vasodilatory and antithrombotic effects, which can reduce neointimal formation [39]. When given systemically, it resulted in early improvement in flow to artificial venous replacement grafts, but this benefit was not sustained [39]. However, use of a spiral delivery catheter to facilitate gene transfer of prostacyclin synthase resulted in reduced in-stent restenosis in a rabbit model, with improved endothelialisation compared with vessels given a control virus after stenting [195].

Cilostazol is a specific inhibitor of cAMP phosphodiesterase III, an enzyme that breaks down cAMP and therefore inhibits platelet aggregation, thrombus formation and SMC migration and proliferation. It can also increase the reendothelialization of the vessel and improve vasodilatation (by increasing nitric oxide levels) [196, 197]. It can limit the development of clinical restenosis when given systemically [39, 198, 199], particularly when coadministered with the antioxidant probucol [200]. When used in pigs, cilostazoleluting stents were effective in reducing neointimal area compared with bare metal stents [197], while cilostazol-rich pluronic gels were able to reduce neointimal formation in injured rat arteries [201].

4.2. Anti-Inflammatory Agents. Inflammation is a major contributor to restenosis, and it has been suggested that the severity of the response to the surgical treatment is not due to the presence of SMC, but due to macrophage content in the lesion [14]. Anti-inflammatory agents inhibit the accumulation and activation of cells at the site of injury, leading to a reduction in growth factor release, cell recruitment and low density lipoprotein absorption and oxidation, thus limiting the degree of neointimal formation [146].

Dexamethasone is an anti-inflammatory steroid that acts by decreasing toll-like receptor signalling (and thus chemokine production), and reducing arachidonic acid metabolism, prostaglandin production and leukocyte recruitment [202, 203]. Targeted delivery techniques may be better than systemic use, as dexamethasone has been associated with the development of latent diabetes, immunosuppression and drug dependency. While locally delivered nanoparticle-encapsulated dexamethasone or periadventitial treatment with silicone polymer-implanted dexamethasone limited neointimal formation in the balloon-injured rat artery [204], high concentrations of stent-bound dexamethasone, while well tolerated in the artery wall, resulted in only a limited reduction in neointimal formation in a pig model [99]. However, stents coated in combined dexamethasone and rapamycin were effective in preventing in-stent restenosis in pig and dog models [205]. Clinical trials of dexamethasone-bound stents have commenced, with favourable early results $[100,206]$. Further trials are underway using a microinfusion catheter to site-deliver dexamethasone (as an antirestenotic agent) to the adventitia via the lumen (http://www.mercatormed.com/).

Liposomes are vesicles composed of lipid bilayers and are readily phagocytosed by inflammatory cells. Liposomemediated delivery of bisphosphonates (alendronate or clodronate) was able to reduce neointimal formation and the infiltration and proliferation of inflammatory cells (macrophages and monocytes) in balloon injured or stented rabbit arteries $[143,144]$. Gallium and gadolinium nanosuspensions of alendronate were similarly able to limit neointimal formation in injured rat arteries [207].

Tranilast, an anti-allergic and anti-inflammatory drug, inhibits the release of growth factors (particularly TGF- $\beta$ ) after experimental neointimal injury, stent implantation or transplantation, limiting neointimal formation. It does this by preventing leukocyte accumulation, SMC migration and proliferation, and collagen and glycosaminoglycan synthesis and accumulation [208-210]. It also reduces prostaglandin and increases nitric oxide production. Small early studies indicated that tranilast reduced the incidence of clinical restenosis $[10,86,211]$, but the much larger PRESTO study indicated that while tranilast reduced the incidence of myocardial infarction, it had no effect on the incidence of restenosis. Treatment was stopped prematurely due to adverse side effects [85]. This drug appears to be a prime candidate for targeted local delivery, as it can influence many of the factors that contribute to the initiation of the restenotic response.

4.3. Antiproliferative and Antimigrating Agents. SMCs respond to injury by migrating, proliferating, and producing extracellular matrix, and this response is often stimulated by growth factors released during injury. These responses occur following change from a "contractile" to a "synthetic" phenotype $[26,27,35]$. If this response to injury can be reduced or eliminated then the restenotic response may be minimised [212]. However, treatments that alter this SMC response should not also decrease the reendothelialization of the vessel.

One major growth factor upregulated in restenotic plaques is TGF- $\beta$, while others (like platelet-derived growth factor (PDGF)) are also know to promote SMC proliferation and phenotypic change $[16,213]$. These growth factors also stimulate SMC production of the inflammatory matrix proteins hyaluronan and versican [116]. Agents that prevent the stimulation of SMC by growth factors, such as trapidil (an antiplatelet drug that also antagonists PDGF [214]) minimise proliferation and migration in animal studies, whether delivered systemically $[214,215]$ or locally [216]. Trapidil can also reduce the rate of clinical restenosis [10, 39, 217]. Locally delivered antisense TGF- $\beta_{1}$, has been administered to arteries via pluronic gels applied to the arterial adventitia, and to vein grafts using nanoparticles, with a subsequent reduction in neointimal thickening $[116,218]$. Tyrphostin (an inhibitor of SMC proliferation by reducing growth factor receptor activity [219]) reduces neointimal formation when applied locally to the adventitia of injured arteries (in pluronic gel). Local delivery of tyrphostin (using the biodegradable organic nanoparticle polylactic acid) following balloon-injury of rat carotid arteries or stenting of porcine coronary arteries was also successful in limiting neointimal formation [142, 220, 221]. These experiments suggest that tyrphostin may be suitable for use in the delivery of antirestenotic therapy independent of stent design or type of injury. 
Angiopeptin, a somatostatin analog, is also thought to inhibit local growth factor activation of SMC. Although effective in reducing neointimal formation in animal models [39, 222], it has conflicting clinical effects when given systemically. Although it reduced the incidence of restenosis in a preliminary trial, it was not effective as an antirestenotic agent in a larger trial $[148,149]$. However, small trials of locally delivered angiopeptin (stent-delivered or catheterdelivered) are more promising $[113,223]$.

Pluronic gels applied to the arterial adventitia have been used in animal models to locally deliver ACE inhibitors [214, 224], with a subsequent reduction in neointimal thickening. This change may be due to improving endothelial cell function, PAI-1 antigen attenuation (thus reducing thrombosis), or due to a decrease in matrix metalloproteinase production and matrix remodelling (thus limiting SMC migration) and SMC proliferation [225].

All of these treatments are designed to reduce the number of SMC present, by limiting SMC proliferation. An alternative approach is to prevent SMC apoptosis, so as to preserve plaque cap thickness. The local delivery of the caspase inhibitor ZVAD-fmk by a delivery catheter inhibited SMC apoptosis and reduced neointimal proliferation without affecting reendothelialization in balloon-injured injured rabbit arteries [226].

Agents that alter matrix composition or lipid-carrying capacity are also potential antirestenotic treatments. Heparan sulphate proteoglycans, present in the immediate environment of SMC, not only act as low affinity receptors for growth factors but also influence cell phenotype [27, 119, 227]. When delivered locally in a pluronic gel they were found to inhibit the formation of the neointima after injury of rabbit carotid arteries [119]. Heparan sulphate proteoglycans and extracellular matrix proteins are degraded by heparanases and metalloproteinases released from vascular cells. Inhibition of these enzymes has been used successfully in culture systems and in animal models of changes after angioplasty, but is not currently suitable for clinical use $[29,66,127,228]$. The ability of the extracellular matrix to store lipid (a pro-restenotic stimulus) can also be altered. Versican is a major matrix protein in restenotic vessels [16, $58,61]$. Balloon-injured arteries in rabbits fed a variable (high-fat/normal) diet were seeded with SMC transduced with versican variant V3. These arteries had less neointimal formation, and increased resistance to lipid deposition and inflammation, due to their altered matrix composition [123].

4.4. Cytostatic and Immunosuppressive Agents. Colchicine binds to tubulin (inhibiting microtubule polymerisation), thus preventing cellular proliferation and migration. It can also inhibit the release of neutrophil-attracting chemokines and act as an anti-inflammatory agent [229]. Colchicine also stops the formation of Weibel-Palade bodies in endothelial cells and decreases the incidence of thrombosis after arterial injury [230]. In culture colchicine reduces the proliferation of human restenotic SMC by 60\% [152], and (in large doses) can reduce stenosis in animal models [231]. Colchicine is quickly cleared after systemic administration, and this may account for its lack of clinical effect in clinical studies. There was a high patient drop-out rate in the clinical trials, due to adverse side effects (despite a reduction in dose from that found optimal in animal studies) $[23,73,76,229,231]$. While an infusion of colchicine via a balloon catheter did not have a long dwell time in rabbit artery walls, its retention was improved by containment within microparticles, resulting in a decrease in neointimal thickening [232].

Paclitaxel (taxol) is an antiproliferative microtubulestabilising agent that is toxic to almost all cells [233]. Thus paclitaxel must be given locally-systemic delivery results in significant adverse symptoms. Facilitating the passage of paclitaxel into the artery wall is more difficult than for other drugs (such as heparin), but once present its hydrophobic nature means that it is more likely to be retained within the wall, and to be present in a greater concentration [234]. Rabbits with paclitaxel-eluting stents and rats given paclitaxel locally via the perivascular route were found to have less stenosis than control animals. However, the arteries had incomplete healing of the endothelium, increased numbers of inflammatory cells, and extensive fibrin and platelet deposition [233, 235-237]. In pigs, paclitaxel given locally via an arterial stent or administered locally to vein grafts or arteriovenous shunts resulted in reduced neointimal formation in the short term $[98,233,238]$, but this benefit was not seen in longer term experiments due to "catch-up" neointimal formation $[98,233]$. Other means of delivering paclitaxel have been investigated, including encapsulating it in multilayered "nanoburrs" that have hooks on their surface that bind to specific peptides on exposed surfaces. These paclitaxel-nanoburrs were found to be cytotoxic to SMC in vitro and preferentially bound to the denuded regions of balloon-injured arteries in rats [239]. Tissue factor-targeted paclitaxel nanoparticles were similarly able to limit SMC proliferation in vitro [133].

Current clinical trials indicate that stents with high doses of paclitaxel are successful at reducing the incidence of restenosis from $5-27 \%$ to $2-9 \%[50,87,114,240,241]$, and may also be effective in reducing vein graft disease $[22,242]$. Longer term studies continue to show the benefit of paclitaxel-eluting stents in the coronary vasculature [109] (but not the periphery [243]). However, late thrombotic events are of concern [24, 25, 244, 245]. Clinical studies have shown the efficacy of paclitaxel-coated balloon catheters in the prevention of restenosis, and it is possible that this form of local delivery may be of benefit in peripheral artery disease $[23,114]$.

Rapamycin (sirolimus) has been used as an anti-fungal agent, antibiotic, antitumour agent and immunosuppressant. It prevents production of antibody-producing cells, delays SMC migration, and inhibits proliferation in SMCs, Tand B-lymphocytes, hepatocytes, fibroblasts and endothelial cells [246-248]. Like paclitaxel, it is lipophilic and minimally soluble in water. It has difficulty entering the artery wall and passing into the cell, where it needs to be in order to exert its effect on mammalian target of rapamycin (mTOR) [23]. It has a positive short-term, high-dose effect in animal models of arterial injury, but only if the drug is given sufficiently early $[205,249,250]$. Animals given rapamycin systemically 
had extensive alterations, even at low doses [251], but the dosing difficulties and systemic changes were overcome by using local delivery techniques. When bound to stents, high doses of rapamycin were found effective in limiting neointimal formation in rabbit iliac arteries [252]. Targeting of nanoparticle-rapamycin conjugates to $\alpha \mathrm{v} \beta 3$ in injured rabbit arteries also limited neointimal formation [135] as did use of a rapamycin-conjugated antibody that recognises cross-linked fibrin [107]. Both forms of targeted delivery resulted in improved reendothelization of the injured vessels, with reduced neointimal formation $[107,135]$.

In fat-fed rabbits, vein grafts given rapamycin periadventitially in pluronic gel had fewer proliferating cells and $80 \%$ less neointimal formation at 28 days after engraftment [253]. Similar experiments on mouse vein grafts found that periadventitial administration of rapamycin in pluronic gel resulted in less neointimal formation at 1-2 weeks after engraftment, but the differences were no longer significant by 4-6 weeks [254]. Pig saphenous veins bathed in rapamycin before engraftment into the carotid artery had a smaller neointimal area at 4 weeks, but by 12 weeks there was no difference between control and experimental grafts [98]. This "catch-up" may be due low dosing (due to rapamycin's low solubility in water) or exhaustion of the drug within the artery wall. Periadventitial administration of rapamycineluting microbeads to extend the rapamycin therapy was investigated, but, once again, while the drug was effective at early time-points, there was catch-up by 12 weeks after engraftment. Increasing the dose of rapamycin led to local toxicity, with graft rupture, inhibition of neoangiogenesis and accelerated neointimal formation [121].

Short to medium term clinical trials of localised delivery of rapamycin (or rapamycin analogues) via stents have found that restenosis is minimal and neointimal hyperplasia is absent for at least 12 months after implantation [83, 84, 88]. However, extensive culture and animal studies have indicated that rapamycin can delay or prevent the recovery of the endothelium, and increase fibrin deposition in blood vessels [205, 255]. In addition, rapamycin immunosuppression is associated with an elevated incidence of hepatic artery occlusion after liver transplantation [256]. Thus, as with paclitaxel-coated stents, there are concerns about the elevated levels of late arterial thrombosis in patients given rapamycin-eluting stent [8, 108, 244, 245, 255, 257]. Thrombosis is also of concern in vein graft disease, as patients whose grafts have been treated with rapamycineluting stents have an increased risk of late death (due to thrombosis) compared with those given a bare metal stent [258]. Many of the new developments in drug-eluting stent therapy are designed to target this problem [100].

4.5. Regulators of Lipid Metabolism. Lipids, recruited into the artery wall from the blood, produce mechanical instability within the plaque. Once activated, lipids also participate in creating oxidative stress and stimulate inflammatory responses [150]. Agents that prevent this aggregation of lipid in the blood or the artery wall, or reduce the oxidation of the lipid components, may be of benefit in reducing the incidence or degree of restenosis. Statins (HMG CoA reductase inhibitors) are lipid lowering drugs with few side effects $[147,259]$. They prevent SMC phenotypic modulation, inhibit SMC proliferation and migration and limit SMC and endothelial cell metalloproteinase production [260264]. They also have immunomodulatory effects and reduce thrombotic risk in patients with cardiovascular disease [264, $265]$, and can reduce neointimal growth in animal models [259, 261].

The proportion of clinical events after stroke, angina, myocardial infarction, or revascularisation is reduced after statin treatment $[79,266,267]$, possibly due to endotheliumprotective and antioxidant effects $[264,268]$. In some trials restenosis rates remained unaltered [269, 270], but other trials found that statin therapy reduced the incidence of restenosis $[271,272]$, possibly by stabilising the plaque and preventing artery remodelling in response to inflammatory stimuli or by or reducing the incidence of thrombosis [263]. Statin therapy also reduces the incidence of in-stent thrombosis in patients with an inflammatory profile [273]. When used in pigs, stent-delivered cerivastatin was found to be effective in improving endothelial function and reducing inflammation and neointimal formation [274].

4.6. Antioxidants. Reactive oxygen species (including superoxide, peroxide, and other free radicals) can be produced by activated leukocytes and after tissue hypoxia (as happens during vein graft preparation). Dietary antioxidants, such as vitamin C (ascorbic acid), vitamin E ( $\alpha$-tocopherol), and $\beta$-carotene (provitamin A) can protect again these reactive oxygen species, by altering the levels of lipoproteins circulating in the blood and inhibiting pro-thrombotic oxidative events in plasma and the artery wall [275, 276]. Generally, increased levels of dietary antioxidants are associated with reduced primary disease risk and reduced recurrence of cardiovascular events [101, 275, 277]. Their use can lead to reduced low density lipoprotein (LDL) formation and oxidation, and reduced LDL deposition in tissues. The antioxidant probucol acts by preventing SMC proliferation and suppressing the release of interleukins from macrophages. It can also reduce SMC metalloproteinase secretion, reverse cholesterol transport and promote positive vascular remodelling [200, 278]. Probucol at high doses can prevent the progression of atherosclerosis in animal models [279]. When given alone, with dosing commencing 30 days before clinical angioplasty, probucol significantly reduced luminal narrowing and the incidence of restenosis, but when given with vitamin supplements its beneficial effect was reduced [280] or eliminated [278, 281, 282].

Composite stents coated with resveratrol and quercetin (polyphenols found abundantly in grapes) were effective in preventing luminal stenosis and inflammation, while promoting reendothelialization of the injured rat artery [283]. This could be a promising additional therapy to prevent late thrombosis after drug-eluting stent placement.

Another way to protect the vasculature against reactive oxygen species is by the administration of nitric oxide, either via gene therapy or directly via nitric oxide donors [33, 39, 120, 139]. Nitric oxide therapy can inhibit platelet aggregation and adhesion, limit leukocyte adhesion, induce 
SMC apoptosis, and reduce vasoconstriction [284]. While systemic delivery has not prevented clinical restenosis [39], local delivery may be more successful. SMC gene therapy of nitric oxide synthase in injured arteries in rats and adventitial delivery of a nitric oxide donor to vein grafts in fat-fed rabbits reduced neointimal formation $[120,149]$, and this therapy is now being extended into clinical trials [139]. Ex vivo experiments indicate that nitric oxide-donating aspirins may be suitable to prevent thrombosis, spasm and possibly neointimal formation in vein grafts $[33,285]$. Vein grafts have increased superoxide levels upon exposure to the arterial environment, and this is known to quench nitric oxide [286]. Catheter or stent-directed gene therapy with extracellular superoxide dismutase has been shown to be effective in improving endothelial cell recovery and preventing in-stent restenosis $[138,287]$ and should also be of benefit in vein grafts.

\section{Future Developments in Antirestenotic and Vein Graft Therapies}

The discovery and refinement of treatments to prevent restenosis and vein graft disease is an active area of medical research. Therapies that require systemic administration have been found wanting, and this has led to considerable interest in developing new delivery systems and improving established targeting techniques. It is also becoming apparent that antirestenotic agents must not just be locally delivered to the appropriate site, but also be supported by some kind of mechanism to hold it in place, whether mechanical as in stents $[23,82,100]$, or physiological, as in the binding of antibodies to fibrin formed at the angioplasty site [106, 107] or incorporation into the artery wall $[123,288]$ for a sufficient time.

However, restenosis and vein graft disease are multifaceted diseases, and administration of a single drug directed at a single aspect of treatment may not be effective at limiting vessel closure [12], particularly if administered for a short time. It may be necessary to administer a number of antirestenotic compounds directed against the various aspects of restenosis-proliferation, matrix formation, inflammation, thrombus incorporation, and remodeling before the problem of restenosis can be avoided. This therapy may take the form of a "5-in-1" treatment, or multidrugloaded nanoparticles, scaffolds or antibodies. Alternately, the delivery a single multi-function drug (possibly held within nanoparticles) effective against many or all of these features may be useful in preventing restenosis. An example of such a drug is tranilast, a drug with antiproliferative, antimigratory, anti-inflammatory, antimatrix synthesis, provasodilatation, and proendothelial properties [85, 86, 208, 209]. Cilostazol is another possible multiaspect candidate, as it too can influence many of the aspects involved in the development of restenosis including thrombus formation, SMC migration and proliferation, reendothelialization of the vessel and vasodilatation (by increasing nitric oxide levels). Although systemic cilostazol therapy is relatively well tolerated (compared with tranilast), site delivery of long-term eluted drug would eliminate patient noncompliance, bleeding (and rebound) complications, differences in dosing regimens, and so forth.

As the degree of neointimal formation and the incidence of thrombus formation have been linked with endothelial cell loss [289], a major improvement would be to ensure that the endothelium within the vessel remains complete and that the endothelial cells can still perform their proper function. Future studies should focus on drugs that preserve or allow rapid recovery of the endothelium, but still prevent restenosis/vein graft disease. Use of adjunct drug or gene delivery therapies that are less immunoresponsive-such as nanoparticles - should also advance antirestenotic therapies, by extending drug retention times, and improving drug activity, bioavailability and release profiles.

These target-delivered multiple-drug therapies will not be easy to design and optimise. Irrespective of which delivery system is selected, the doses of the drugs and the separate release kinetics need to be established. These may be controlled, perhaps, by encapsulation in microspheres or nanoparticles, or by layering polymers or using biodegradable polymers. In addition, as different aspects of restenosis may need to be targeted, the timing of the release of the drugs may need to be staggered, perhaps by coating multiple layers of products together, which may also be useful in preventing premature exhaustion of the therapy. A combined therapy should also eliminate the necessity of additional therapies (such as the taking of antithrombotic agents with drugeluting stents), thus eliminating "rebound" thrombosis and the possibility of noncompliance.

Restenosis and vein graft disease are the "Achilles heel" of surgical treatments for atherosclerosis. Current targeted treatments have already considerably reduced the degree and incidence of restenosis and vein graft disease, and on-going refinements will further improve these therapies.

\section{Acknowledgment}

The author's work is supported by the British Heart Foundation.

\section{References}

[1] World Health Organization, Cardiovascular diseases (CVDs). Fact sheet No 317, 2011.

[2] J. G. Motwani and E. J. Topol, "Aortocoronary saphenous vein graft disease: pathogenesis, predisposition, and prevention," Circulation, vol. 97, no. 9, pp. 916-931, 1998.

[3] M. R. Bennett, "In-stent stenosis: pathology and implications for the development of drug eluting stents," Heart, vol. 89, no. 2, pp. 218-224, 2003.

[4] C. Landau, R. A. Lange, and L. D. Hillis, "Percutaneous transluminal coronary angioplasty," The New England Journal of Medicine, vol. 330, no. 14, pp. 981-993, 1994.

[5] Y. Asakura, M. Suzuki, H. Nonogi et al., "Restenosis after percutaneous transluminal coronary angioplasty in patients with non-insulin-dependent diabetes mellitus (NIDDM)," Journal of Cardiovascular Risk, vol. 5, no. 5-6, pp. 331-334, 1998.

[6] C. E. Hagemeyer and K. Peter, "Ex-vivo thrombolytic gene therapy for vein graft patency: the frontier for development 
of selective, localised therapeutic approaches," Thrombosis and Haemostasis, vol. 102, no. 1, pp. 3-4, 2009.

[7] Y. C. Chan and S. W. Cheng, "Drug-eluting stents and balloons in peripheral arterial disease: evidence so far," International Journal of Clinical Practice, vol. 65, no. 6, pp. 664-668, 2011.

[8] J. Y. Lee, D. W. Park, Y. H. Kim et al., "Incidence, predictors, treatment, and long-term prognosis of patients with restenosis after drug-eluting stent implantation for unprotected left main coronary artery disease," Journal of the American College of Cardiology, vol. 57, no. 12, pp. 1349-1358, 2011.

[9] R. S. Schwartz, D. R. Holmes, and E. J. Topol, "The restenosis paradigm revisited: an alternative proposal for cellular mechanisms," Journal of the American College of Cardiology, vol. 20, no. 5, pp. 1284-1293, 1992.

[10] J. Lefkovits and E. J. Topol, "Pharmacological approaches for the prevention of restenosis after percutaneous coronary intervention," Progress in Cardiovascular Diseases, vol. 40, no. 2, pp. 141-158, 1997.

[11] R. Komatsu, M. Ueda, T. Naruko, A. Kojima, and A. E. Becker, "Neointimal tissue response at sites of coronary stenting in humans: macroscopic, histological, and immunohistochemical analyses," Circulation, vol. 98, no. 3, pp. 224233, 1998.

[12] M. R. Bennett and M. O'Sullivan, "Mechanisms of angioplasty and stent restenosis: implications for design of rational therapy," Pharmacology and Therapeutics, vol. 91, no. 2, pp. 149-166, 2001.

[13] P. M. Steele, J. H. Chesebro, A. W. Stanson et al., "Balloon angioplasty: natural history of the pathophysiological response to injury in a pig model," Circulation Research, vol. 57, no. 1, pp. 105-112, 1985.

[14] P. R. Moreno, V. H. Bernardi, J. López-Cuéllar et al., "Macrophage infiltration predicts restenosis after coronary intervention in patients with unstable angina," Circulation, vol. 94, no. 12, pp. 3098-3102, 1996.

[15] R. Gallo, A. Padurean, V. Toschi et al., "Prolonged thrombin inhibition reduces restenosis after balloon angioplasty in porcine coronary arteries," Circulation, vol. 97, no. 6, pp. 581-588, 1998.

[16] I. M. Chung, H. K. Gold, S. M. Schwartz, Y. Ikari, M. A. Reidy, and T. N. Wight, "Enhanced extracellular matrix accumulation in restenosis of coronary arteries after stent deployment," Journal of the American College of Cardiology, vol. 40, no. 12, pp. 2072-2081, 2002.

[17] D. Mehta, S. J. George, J. Y. Jeremy et al., "External stenting reduces long-term medial and neointimal thickening and platelet derived growth factor expression in a pig model of arteriovenous bypass grafting," Nature Medicine, vol. 4, no. 2, pp. 235-239, 1998.

[18] H. Bult, "Restenosis: a challenge for pharmacology," Trends in Pharmacological Sciences, vol. 21, no. 7, pp. 274-279, 2000.

[19] E. R. Edelman and M. J. Karnovsky, "Contrasting effects of the intermittent and continuous administration of heparin in experimental restenosis," Circulation, vol. 89, no. 2, pp. 770776, 1994.

[20] A. Lafont and D. Faxon, "Why do animal models of postangioplasty restenosis sometimes poorly predict the outcome of clinical trials?" Cardiovascular Research, vol. 39, no. 1, pp. 50-59, 1998.

[21] R. L. Wilensky, J. F. Tanguay, S. Ito et al., "Heparin infusion prior to stenting (HIPS) trial: final results of a prospective, randomized, controlled trial evaluating the effects of local vascular delivery on intimal hyperplasia," American Heart Journal, vol. 139, no. 6, pp. 1061-1070, 2000.

[22] E. S. Brilakis, C. Lichtenwalter, J. A. de Lemos et al., "A randomized controlled trial of a paclitaxel-eluting stent versus a similar bare-metal stent in saphenous vein graft lesions the SOS (Stenting of Saphenous Vein Grafts) trial," Journal of the American College of Cardiology, vol. 53, no. 11, pp. 919-928, 2009.

[23] Z. M. Gertz and R. L. Wilensky, "Local drug delivery for treatment of coronary and peripheral artery disease," Cardiovascular Therapeutics, vol. 29, no. 6, pp. e54-e66, 2011.

[24] G. Nakazawa, E. Ladich, A. V. Finn, and R. Virmani, "Pathophysiology of vascular healing and stent mediated arterial injury," EuroIntervention, vol. 4, pp. C7-C10, 2008.

[25] X. Flores-Ríos, R. Marzoa-Rivas, J. P. Abugattás-de Torres et al., "Late thrombosis of paclitaxel-eluting stents: long-term incidence, clinical consequences, and risk factors in a cohort of 604 patients," American Heart Journal, vol. 155, no. 4, pp. 648-653, 2008.

[26] G. R. Campbell and J. H. Campbell, "Smooth muscle phenotypic changes in arterial wall homeostasis: implications for the pathogenesis of atherosclerosis," Experimental and Molecular Pathology, vol. 42, no. 2, pp. 139-162, 1985.

[27] J. H. Campbell and G. R. Campbell, "Smooth muscle phenotypic modulation-a personal experience," Arteriosclerosis, Thrombosis, and Vascular Biology, vol. 32, no. 8, pp. 17841789, 2012

[28] S. J. George, A. B. Zaltsman, and A. C. Newby, "Surgical preparative injury and neointima formation increase MMP9 expression and MMP-2 activation in human saphenous vein," Cardiovascular Research, vol. 33, no. 2, pp. 447-459, 1997.

[29] M. Fitzgerald, I. P. Hayward, A. C. Thomas, G. R. Campbell, and J. H. Campbell, "Matrix metalloproteinases can facilitate the heparanase-induced promotion of phenotypic change in vascular smooth muscle cells," Atherosclerosis, vol. 145, no. 1, pp. 97-106, 1999.

[30] J. L. Johnson, G. J. J. M. van Eys, G. D. Angelini, and S. J. George, "Injury induces dedifferentiation of smooth muscle cells and increased matrix-degrading metalloproteinase activity in human saphenous vein," Arteriosclerosis, Thrombosis, and Vascular Biology, vol. 21, no. 7, pp. 1146$1151,2001$.

[31] R. M. Zwolak, M. C. Adams, and A. W. Clowes, "Kinetics of vein graft hyperplasia: association with tangential stress," Journal of Vascular Surgery, vol. 5, no. 1, pp. 126-136, 1987.

[32] B. Howden, P. Jablonski, M. Biguzas et al., "Effect of allopurinol superoxide-dismutase and catalase on renaltransplants in the rat," Kidney International, vol. 35, no. 2, p. 746, 1989.

[33] J. Y. Jeremy, N. Shukla, S. Muzaffar, A. Handley, and G. D. Angelini, "Reactive oxygen species, vascular disease and cardiovascular surgery," Current Vascular Pharmacology, vol. 2, no. 3, pp. 229-236, 2004.

[34] M. Kirchengast and K. Münter, "Endothelin and restenosis," Cardiovascular Research, vol. 39, no. 3, pp. 550-555, 1998.

[35] R. Zargham, "Preventing restenosis after angioplasty: a multistage approach," Clinical Science, vol. 114, no. 3-4, pp. 257-264, 2008.

[36] Y. Honda and P. J. Fitzgerald, "The renaissance of directional coronary atherectomy: a second look from the inside," The Journal of Invasive Cardiology, vol. 13, no. 11, pp. 748-751, 2001. 
[37] S. Mishra, R. M. Wolfram, R. Torguson et al., "Comparison of effectiveness and safety of drug-eluting stents versus vascular brachytherapy for saphenous vein graft in-stent restenosis," American Journal of Cardiology, vol. 97, no. 9, pp. 1303-1307, 2006.

[38] C. Di Mario, R. Gil, E. Camenzind et al., "Quantitative assessment with intracoronary ultrasound of the mechanisms of restenosis after percutaneous transluminal coronary angioplasty and directional coronary atherectomy," American Journal of Cardiology, vol. 75, no. 12, pp. 772-777, 1995.

[39] R. M. Schainfeld, "Potential emerging therapeutic strategies to prevent restenosis in the peripheral vasculature," Catheterization and Cardiovascular Interventions, vol. 56, no. 3, pp. 421-431, 2002.

[40] O. F. Bertrand, R. Sipehia, R. Mongrain et al., "Biocompatibility aspects of new stent technology," Journal of the American College of Cardiology, vol. 32, no. 3, pp. 562-571, 1998.

[41] C. S. Wong, M. B. Leon, and J. J. Popma, "New device angioplasty: the impact on restenosis," Coronary Artery Disease, vol. 4, no. 3, pp. 243-253, 1993.

[42] G. W. Stone, E. de Marchena, D. Dageforde et al., "Prospective, randomized, multicenter comparison of laser-facilitated balloon angioplasty versus stand-alone balloon angioplasty in patients with obstructive coronary artery disease," Journal of the American College of Cardiology, vol. 30, no. 7, pp. 17141721, 1997.

[43] R. Köster, C. W. Hamm, R. Seabra-Gomes et al., "Laser angioplasty of restenosed coronary stents: results of a multicenter surveillance trial," Journal of the American College of Cardiology, vol. 34, no. 1, pp. 25-32, 1999.

[44] G. R. Giugliano, M. W. Falcone, D. Mego et al., "A prospective multicenter registry of laser therapy for degenerated saphenous vein graft stenosis: the COronary graft Results following Atherectomy with Laser (CORAL) trial," Cardiovascular Revascularization Medicine, vol. 13, no. 2, pp. 84-89, 2012.

[45] P. Zilla, P. Human, M. Wolf et al., "Constrictive external nitinol meshes inhibit vein graft intimal hyperplasia in nonhuman primates," The Journal of Thoracic and Cardiovascular Surgery, vol. 136, no. 3, pp. 717-725, 2008.

[46] F. Versaci, A. Gaspardone, F. Tomai, F. Crea, L. Chiariello, and P. A. Gioffrè, "A comparison of coronary-artery stenting with angioplasty for isolated stenosis of the proximal left anterior descending coronary artery," The New England Journal of Medicine, vol. 336, no. 12, pp. 817-822, 1997.

[47] J. Escaned, J. Goicolea, F. Alfonso et al., "Propensity and mechanisms of restenosis in different coronary stent designs: complementary value of the analysis of the luminal gain-loss relationship," Journal of the American College of Cardiology, vol. 34, no. 5, pp. 1490-1497, 1999.

[48] M. A. Bettmann, B. T. Katzen, J. Whisnant et al., "Carotid stenting and angioplasty: a statement for healthcare professionals from the councils on cardiovascular radiology, stroke, cardio-thoracic and vascular surgery, epidemiology and prevention, and clinical cardiology, American Heart Association," Circulation, vol. 97, no. 1, pp. 121-123, 1998.

[49] R. Virmani, F. Liistro, G. Stankovic et al., "Mechanism of late in-stent restenosis after implantation of a paclitaxel derivateeluting polymer stent system in humans," Circulation, vol. 106, no. 21, pp. 2649-2651, 2002.

[50] R. Tung, S. Kaul, G. A. Diamond, and P. K. Shah, "Narrative review: drug-eluting stents for the management of restenosis: a critical appraisal of the evidence," Annals of Internal Medicine, vol. 144, no. 12, pp. 913-919, 2006.

[51] A. Anzuini, S. Rosanio, V. Legrand et al., "Wiktor stent for treatment of chronic total coronary artery occlusions: shortand long-term clinical and angiographic results from a large multicenter experience," Journal of the American College of Cardiology, vol. 31, no. 2, pp. 281-288, 1998.

[52] J. M. Ahmed, G. S. Mintz, N. J. Weissman et al., "Mechanism of lumen enlargement during intracoronary stent implantation: an intravascular ultrasound study," Circulation, vol. 102, no. 1, pp. 7-10, 2000.

[53] B. Reimers, I. Moussa, T. Akiyama et al., "Long-term clinical follow-up after successful repeat percutaneous intervention for stent restenosis," Journal of the American College of Cardiology, vol. 30, no. 1, pp. 186-192, 1997.

[54] H. Eltchaninoff, R. Koning, C. Tron, V. Gupta, and A. Cribier, "Balloon angioplasty for the treatment of coronary in-stent restenosis: immediate results and 6-month angiographic recurrent restenosis rate," Journal of the American College of Cardiology, vol. 32, no. 4, pp. 980-984, 1998.

[55] G. E. Austin, N. B. Ratliff, J. Hollman et al., "Intimal proliferation of smooth muscle cells as an explanation for recurrent coronary artery stenosis after percutaneous transluminal coronary angioplasty," Journal of the American College of Cardiology, vol. 6, no. 2, pp. 369-375, 1985.

[56] K. N. Garratt, D. R. Holmes, M. R. Bell et al., "Restenosis after directional coronary atherectomy: differences between primary atheromatous and restenosis lesions and influence of subintimal tissue resection," Journal of the American College of Cardiology, vol. 16, no. 7, pp. 1665-1671, 1990.

[57] L. A. Guzman, M. J. Mick, A. M. Arnold, F. Forudi, and P. L. Whitlow, "Role of intimal hyperplasia and arterial remodeling after balloon angioplasty: an experimental study in the atherosclerotic rabbit model," Arteriosclerosis, Thrombosis, and Vascular Biology, vol. 16, no. 3, pp. 479-487, 1996.

[58] T. N. Wight and M. J. Merrilees, "Proteoglycans in atherosclerosis and restenosis: key roles for versican," Circulation Research, vol. 94, no. 9, pp. 1158-1167, 2004.

[59] E. R. O’Brien, S. Urieli-Shoval, M. R. Garvin et al., "Replication in restenotic atherectomy tissue," Atherosclerosis, vol. 152, no. 1, pp. 117-126, 2000.

[60] R. Riessen, J. M. Isner, E. Blessing, C. Loushin, S. Nikol, and T. N. Wight, "Regional differences in the distribution of the proteoglycans biglycan and decorin in the extracellular matrix of atherosclerotic and restenotic human coronary arteries," American Journal of Pathology, vol. 144, no. 5, pp. 962-974, 1994.

[61] T. N. Wight, S. Lara, R. Riessen, R. Le Baron, and J. Isner, "Selective deposits of versican in the extracellular matrix of restenotic lesions from human peripheral arteries," American Journal of Pathology, vol. 151, no. 4, pp. 963-973, 1997.

[62] T. Ohara, S. Nanto, S. Asada et al., "Electron-microscopical evaluation of repeat PTCA for restenosis," Circulation, vol. 80, supplement 2, p. II-65, 1989.

[63] D. E. Johnson, T. Hinohara, M. R. Selmon, L. J. Braden, and J. B. Simpson, "Primary peripheral arterial stenoses and restenoses excised by transluminal atherectomy: a histopathologic study," Journal of the American College of Cardiology, vol. 15, no. 2, pp. 419-425, 1990.

[64] C. Bauters, T. Meurice, M. Hamon, E. McFadden, J. M. Lablanche, and M. E. Bertrand, "Mechanisms and prevention of restenosis: from experimental models to clinical practice," Cardiovascular Research, vol. 31, no. 6, pp. 835-846, 1996. 
[65] F. Alfonso, P. Rodriguez, P. Phillips et al., "Clinical and angiographic implications of coronary stenting in thrombuscontaining lesions," Journal of the American College of Cardiology, vol. 29, no. 4, pp. 725-733, 1997.

[66] G. Pasterkamp, D. P. V. de Kleijn, and C. Borst, "Arterial remodeling in atherosclerosis, restenosis and after alteration of blood flow: potential mechanisms and clinical implications," Cardiovascular Research, vol. 45, no. 4, pp. 843-852, 2000.

[67] M. R. Ward, G. Pasterkamp, A. C. Yeung, and C. Borst, "Arterial remodeling. Mechanisms and clinical implications," Circulation, vol. 102, no. 10, pp. 1186-1191, 2000.

[68] B. J. G. L. de Smet, D. de Kleijn, R. Hanemaaijer et al., "Metalloproteinase inhibition reduces constrictive arterial remodeling after balloon angioplasty: a study in the atherosclerotic Yucatan micropig," Circulation, vol. 101, no. 25, pp. 2962-2967, 2000.

[69] S. A. Berceli, Z. Jiang, N. V. Klingman et al., "Differential expression and activity of matrix metalloproteinases during flow-modulated vein graft remodeling," Journal of Vascular Surgery, vol. 39, no. 5, pp. 1084-1090, 2004.

[70] M. P. Anstadt, D. L. Franga, V. Portik-Dobos et al., "Native matrix metalloproteinase characteristics may influence early stenosis of venous versus arterial coronary artery bypass grafting conduits," Chest, vol. 125, no. 5, pp. 1853-1858, 2004.

[71] A. W. Clowes, M. A. Reidy, and M. M. Clowes, "Mechanisms of stenosis after arterial injury," Laboratory Investigation, vol. 49, no. 2, pp. 208-215, 1983.

[72] M. J. Post, C. Borst, and R. E. Kuntz, "The relative importance of arterial remodeling compared with intimal hyperplasia in lumen renarrowing after balloon angioplasty: a study in the normal rabbit and the hypercholesterolemic Yucatan micropig," Circulation, vol. 89, no. 6, pp. 2816-2821, 1994.

[73] J. H. O’Keefe, B. D. McCallister, T. M. Bateman, D. L. Kuhnlein, R. W. Ligon, and G. O. Hartzler, "Ineffectiveness of colchicine for the prevention of restenosis after coronary angioplasty," Journal of the American College of Cardiology, vol. 19, no. 7, pp. 1597-1600, 1992.

[74] D. P. Faxon, T. E. Spiro, S. Minor et al., "Low molecular weight heparin in prevention of restenosis after angioplasty. Results of enoxaparin restenosis (ERA) trial," Circulation, vol. 90, no. 2, pp. 908-914, 1994.

[75] M. J. Brack, S. Ray, A. Chauhan et al., "The subcutaneous heparin and angioplasty restenosis prevention (SHARP) trial. Results of a multicenter randomized trial investigating the effects of high dose unfractionated heparin on angiographic restenosis and clinical outcome," Journal of the American College of Cardiology, vol. 26, no. 4, pp. 947-954, 1995.

[76] M. Freed, R. D. Safian, W. W. O’Neill, M. Safian, D. Jones, and C. L. Grines, "Combination of lovastatin, enalapril, and colchicine does not prevent restenosis after percutaneous transluminal coronary angioplasty," American Journal of Cardiology, vol. 76, no. 16, pp. 1185-1188, 1995.

[77] P. W. Serruys, J. P. R. Herrman, R. Simon et al., "A comparison of hirudin with heparin in the prevention of restenosis after coronary angioplasty," The New England Journal of Medicine, vol. 333, no. 12, pp. 757-763, 1995.

[78] J. A. Cairns, J. Gill, B. Morton et al., "Fish oils and lowmolecular-weight heparin for the reduction of restenosis after percutaneous transluminal coronary angioplasty: the EMPAR study," Circulation, vol. 94, no. 7, pp. 1553-1560, 1996.
[79] J. A. Herd, C. M. Ballantyne, J. A. Farmer et al., "Effects of fluvastatin on coronary atherosclerosis in patients with mild to moderate cholesterol elevations (Lipoprotein and Coronary Atherosclerosis Study [LCAS])," American Journal of Cardiology, vol. 80, no. 3, pp. 278-286, 1997.

[80] J. M. Lablanche, E. P. McFadden, N. Meneveau et al., "Effect of nadroparin, a low-molecular-weight heparin, on clinical and angiographic restenosis after coronary balloon angioplasty: the FACT study. Fraxiparine Angioplastie Coronaire Transluminale," Circulation, vol. 96, no. 10, pp. 3396-3402, 1997.

[81] L. W. Gimple, H. C. Herrmann, M. Winniford, and E. Mammen, "Usefulness of subcutaneous low molecular weight heparin (ardeparin) for reduction of restenosis after percutaneous transluminal coronary angioplasty," American Journal of Cardiology, vol. 83, no. 11, pp. 1524-1529, 1999.

[82] R. S. Kiesz, P. Buszman, J. L. Martin et al., "Local delivery of enoxaparin to decrease restenosis after stenting: results of initial multicenter trial: Polish-American Local Lovenox NIR Assessment study (The POLONIA study)," Circulation, vol. 103, no. 1, pp. 26-31, 2001.

[83] J. E. Sousa, M. A. Costa, A. C. Abizaid et al., "Sustained suppression of neointimal proliferation by sirolimus-eluting stents: one-year angiographic and intravascular ultrasound follow-up," Circulation, vol. 104, no. 17, pp. 2007-2011, 2001.

[84] M. C. Morice, P. W. Serruys, and J. E. Sousa, "A randomized comparison of a sirolimus-eluting stent with a standard stent for coronary revascularization," The New England Journal of Medicine, vol. 346, no. 23, pp. 1773-1780, 2002.

[85] D. R. Holmes, M. Savage, J. M. Lablanche et al., "Results of prevention of restenosis with tranilast and its outcomes (PRESTO) trial," Circulation, vol. 106, no. 10, pp. 1243-1250, 2002.

[86] H. Tamai, K. Katoh, T. Yamaguchi et al., "The impact of tranilast on restenosis after coronary angioplasty: the Second Tranilast Restenosis Following Angioplasty Trial (TREAT-2)," American Heart Journal, vol. 143, no. 3, pp. 506-513, 2002.

[87] A. Colombo, J. Drzewiecki, A. Banning et al., "Randomized study to assess the effectiveness of slow- and moderaterelease polymer-based paclitaxel-eluting stents for coronary artery lesions," Circulation, vol. 108, no. 7, pp. 788-794, 2003.

[88] G. Weisz, J. W. Moses, P. S. Teirstein et al., "Safety of sirolimus-eluting stenting and its effect on restenosis in patients with unstable angina pectoris (a SIRIUS substudy)," American Journal of Cardiology, vol. 99, no. 8, pp. 1044-1050, 2007.

[89] S. Ylä-Herttuala, J. E. Markkanen, and T. T. Rissanen, "Gene therapy for ischemic cardiovascular diseases: some lessons learned from the first clinical trials," Trends in Cardiovascular Medicine, vol. 14, no. 8, pp. 295-300, 2004.

[90] H. Williams, J. L. Johnson, K. G. S. Carson, and C. L. Jackson, "Characteristics of intact and ruptured atherosclerotic plaques in brachiocephalic arteries of apolipoprotein E knockout mice," Arteriosclerosis, Thrombosis, and Vascular Biology, vol. 22, no. 5, pp. 788-792, 2002.

[91] R. Virmani, A. P. Burke, F. D. Kolodgie, and A. Farb, "Pathology of the thin-cap fibroatheroma: a type of vulnerable plaque," Journal of Interventional Cardiology, vol. 16, no. 3, pp. 267-272, 2003.

[92] J. Y. Jeremy and A. C. Thomas, "Animal models for studying neointima formation," Current Vascular Pharmacology, vol. 8, no. 2, pp. 198-219, 2010. 
[93] A. C. Thomas, "Animal models for studying vein graft failure and therapeutic interventions," Current Opinion in Pharmacology, vol. 12, no. 2, pp. 121-126, 2012.

[94] J. J. Badimon, A. F. Ortiz, B. Meyer et al., "Different response to balloon angioplasty of carotid and coronary arteries: effects on acute platelet deposition and intimal thickening," Atherosclerosis, vol. 140, no. 2, pp. 307-314, 1998.

[95] A. C. Thomas and J. H. Campbell, "Differences in response of rat and rabbit arteries to injury," Biomedical Research, vol. 11, no. 2, pp. 189-196, 2000.

[96] J. Holm and G. K. Hansson, "Cellular and immunologic features of carotid artery disease in man and experimental animal models," European Journal of Vascular Surgery, vol. 4, no. 1, pp. 49-55, 1990.

[97] N. F. Worth, C. L. Berry, A. C. Thomas, and J. H. Campbell, "S18886, a selective TP receptor antagonist, inhibits development of atherosclerosis in rabbits," Atherosclerosis, vol. 183, no. 1, pp. 65-73, 2005.

[98] G. J. Murphy, T. W. Johnson, M. H. Chamberlain et al., "Short- and long-term effects of cytochalasin D, paclitaxel and rapamycin on wall thickening in experimental porcine vein grafts," Cardiovascular Research, vol. 73, no. 3, pp. 607617, 2007.

[99] A. M. Lincoff, E. J. Topol, and S. G. Ellis, "Local drug delivery for the prevention of restenosis: fact, fancy, and future," Circulation, vol. 90, no. 4, pp. 2070-2084, 1994.

[100] J. Steffel, F. R. Eberli, T. F. Lüscher, and F. C. Tanner, "Drug-eluting stents-what should be improved?" Annals of Medicine, vol. 40, no. 4, pp. 242-252, 2008.

[101] B. R. Landzberg, W. H. Frishman, and K. Lerrick, "Pathophysiology and pharmacological approaches for prevention of coronary artery restenosis following coronary artery balloon angioplasty and related procedures," Progress in Cardiovascular Diseases, vol. 39, no. 4, pp. 361-398, 1997.

[102] D. J. Hayzer, I. M. Lubin, and M. S. Runge, "Conjugation of plasminogen activators and fibrin-specific antibodies to improve thrombolytic therapeutic agents," Bioconjugate Chemistry, vol. 2, no. 5, pp. 301-308, 1991.

[103] C. Bode, S. R. Hanson, J. F. Schmedtje et al., "Antithrombotic potency of hirudin is increased in nonhuman primates by fibrin targeting," Circulation, vol. 95, no. 4, pp. 800-804, 1997.

[104] J. F. Liang, Y. J. Park, H. Song, Y. T. Li, and V. C. M. Yang, "ATTEMPTS: a heparin/protamine-based prodrug approach for delivery of thrombolytic drugs," Journal of Controlled Release, vol. 72, no. 1-3, pp. 145-156, 2001.

[105] K. Peter, A. Gupta, T. Nordt, S. Bauer, M. S. Runge, and C. Bode, "Construction and in vitro testing of a novel fabhirudin-based fusion protein that targets fibrin and inhibits thrombin in a factor Xa-dependent manner," Journal of Cardiovascular Pharmacology, vol. 42, no. 2, pp. 237-244, 2003.

[106] A. C. Thomas and J. H. Campbell, "Targeted delivery of heparin and LMWH using a fibrin antibody prevents restenosis," Atherosclerosis, vol. 176, no. 1, pp. 73-81, 2004.

[107] A. C. Thomas and J. H. Campbell, "Conjugation of an antibody to cross-linked fibrin for targeted delivery of antirestenotic drugs," Journal of Controlled Release, vol. 100, no. 3, pp. 357-377, 2004.

[108] J. Daemen, N. Kukreja, P. H. van Twisk et al., "Four-year clinical follow-up of the rapamycin-eluting stent evaluated at Rotterdam Cardiology Hospital registry," American Journal of Cardiology, vol. 101, no. 8, pp. 1105-1111, 2008.
[109] S. Silber, A. Colombo, A. P. Banning et al., "Final 5-year results of the TAXUS II trial: a randomized study to assess the effectiveness of slow-and moderate-release polymer-based paclitaxel-eluting stents for de novo coronary artery lesions," Circulation, vol. 120, no. 15, pp. 1498-1504, 2009.

[110] C. J. McKenna, D. R. Holmes, and R. S. Schwartz, "Novel stents for the prevention of restenosis," Trends in Cardiovascular Medicine, vol. 7, no. 7, pp. 245-249, 1997.

[111] M. I. Papafaklis, Y. S. Chatzizisis, K. K. Naka et al., "Drug-eluting stent restenosis: effect of drug type, release kinetics, hemodynamics and coating strategy," Pharmacology \& Therapeutics, vol. 134, no. 1, pp. 43-53, 2012.

[112] M. Chorny, I. Fishbein, and G. Golomb, "Drug delivery systems for the treatment of restenosis," Critical Reviews in Therapeutic Drug Carrier Systems, vol. 17, no. 3, pp. 249-284, 2000.

[113] S. R. Bailey, "Local drug delivery: current applications," Progress in Cardiovascular Diseases, vol. 40, no. 2, pp. 183204, 1997.

[114] C. Herdeg, K. Göhring-Frischholz, K. K. Haase et al., "Catheter-based delivery of fluid paclitaxel for prevention of restenosis in native coronary artery lesions after stent implantation," Circulation, vol. 2, no. 4, pp. 294-301, 2009.

[115] D. Brieger and E. Topol, "Local drug delivery systems and prevention of restenosis," Cardiovascular Research, vol. 35, no. 3, pp. 405-413, 1997.

[116] M. J. Merrilees, B. Beaumont, L. Scott, V. Hermanutz, and P. Fennessy, "Effect of TGF- $\beta 1$ antisense S-oligonucleotide on synthesis and accumulation of matrix proteoglycans in balloon catheter-injured neointima of rabbit carotid arteries," Journal of Vascular Research, vol. 37, no. 1, pp. 5060, 2000.

[117] M. A. Lovich and E. R. Edelman, "Tissue concentration of heparin, not administered dose, correlates with the biological response of injured arteries in vivo," Proceedings of the National Academy of Sciences of the United States of America, vol. 96, no. 20, pp. 11111-11116, 1999.

[118] E. R. Edelman, D. H. Adams, and M. J. Karnovsky, "Effect of controlled adventitial heparin delivery on smooth muscle cell proliferation following endothelial injury," Proceedings of the National Academy of Sciences of the United States of America, vol. 87, no. 10, pp. 3773-3777, 1990.

[119] J. A. Bingley, I. P. Hayward, J. H. Campbell, and G. R. Campbell, "Arterial heparan sulfate proteoglycans inhibit vascular smooth muscle cell proliferation and phenotype change in vitro and neointimal formation in vivo," Journal of Vascular Surgery, vol. 28, no. 2, pp. 308-318, 1998.

[120] A. Chaux, X. M. Ruan, M. C. Fishbein et al., "Perivascular delivery of a nitric oxide donor inhibits neointimal hyperplasia in vein grafts implanted in the arterial circulation," The Journal of Thoracic and Cardiovascular Surgery, vol. 115, no. 3, pp. 604-614, 1998.

[121] T. Rajathurai, S. I. Rizvi, H. Lin, G. D. Angelini, A. C. Newby, and G. J. Murphy, "Periadventitial rapamycin-eluting microbeads promote vein graft disease in long-term pig veininto-artery interposition grafts," Circulation, vol. 3, no. 2, pp. 157-165, 2010.

[122] H. M. Nugent, Y. S. Ng, D. White, A. Groothius, G. Kanner, and E. R. Edelman, "Delivery site of perivascular endothelial cell matrices determines control of stenosis in a porcine femoral stent model," Journal of Vascular and Interventional Radiology, vol. 20, no. 12, pp. 1617-1624, 2009. 
[123] M. J. Merrilees, B. W. Beaumont, K. R. Braun et al., "Neointima formed by arterial smooth muscle cells expressing versican variant $\mathrm{V} 3$ is resistant to lipid and macrophage accumulation," Arteriosclerosis, Thrombosis, and Vascular Biology, vol. 31, no. 6, pp. 1309-1316, 2011.

[124] S. J. White and A. C. Newby, "Gene therapy for all aspects of vein-graft disease," Journal of Cardiac Surgery, vol. 17, no. 6, pp. 549-555, 2002.

[125] A. C. Thomas, M. J. Wyatt, and A. C. Newby, "Reduction of early vein graft thrombosis by tissue plasminogen activator gene transfer," Thrombosis and Haemostasis, vol. 102, no. 1, pp. 145-152, 2009.

[126] M. J. Underwood, G. Cooper, R. More et al., "Effect of intraluminal application of tissue-type plasminogen activator on the fibrinolytic activity of experimental vein grafts," Cardiovascular Research, vol. 29, no. 3, pp. 422-427, 1995.

[127] S. J. George, C. T. Lloyd, G. D. Angelini, A. C. Newby, and A. H. Baker, "Inhibition of late vein graft neointima formation in human and porcine models by adenovirus-mediated overexpression of tissue inhibitor of metalloproteinase-3," Circulation, vol. 101, no. 3, pp. 296-304, 2000.

[128] P. Ehrlich, "Address in pathology, 'On Chemotherapy': delivered before the Seventeenth International Congress of Medicine," British Medical Journal, vol. 2, no. 2746, pp. 353359, 1913.

[129] C. Bode, M. Hudelmayer, P. Mehwald et al., "Fibrin-targeted recombinant hirudin inhibits fibrin deposition on experimental clots more efficiently than recombinant hirudin," Circulation, vol. 90, no. 4, pp. 1956-1963, 1994.

[130] A. C. Thomas and J. H. Campbell, "Timecourse of fibrin deposition and removal after arterial injury," Thrombosis Research, vol. 109, no. 1, pp. 65-69, 2003.

[131] Z. Gu, B. E. Rolfe, Z. P. Xu et al., "Antibody-targeted drug delivery to injured arteries using layered double hydroxide nanoparticles," Advanced Healthcare Materials, vol. 1, no. 5, pp. 669-673, 2012.

[132] B. J. Lestini, S. M. Sagnella, Z. Xu et al., "Surface modification of liposomes for selective cell targeting in cardiovascular drug delivery," Journal of Controlled Release, vol. 78, no. 1-3, pp. 235-247, 2002.

[133] G. M. Lanza, X. Yu, P. M. Winter et al., "Targeted antiproliferative drug delivery to vascular smooth muscle cells with a magnetic resonance imaging nanoparticle contrast agent: implications for rational therapy of restenosis," Circulation, vol. 106, no. 22, pp. 2842-2847, 2002.

[134] S. A. Wickline, A. M. Neubauer, P. Winter, S. Caruthers, and G. Lanza, "Applications of nanotechnology to atherosclerosis, thrombosis, and vascular biology," Arteriosclerosis, Thrombosis, and Vascular Biology, vol. 26, no. 3, pp. 435-441, 2006.

[135] T. Cyrus, H. Zhang, J. S. Allen et al., "Intramural delivery of rapamycin with $\alpha \mathrm{v} \beta 3$-targeted paramagnetic nanoparticles inhibits stenosis after balloon injury," Arteriosclerosis, Thrombosis, and Vascular Biology, vol. 28, no. 5, pp. 820-826, 2008.

[136] R. V. J. Chari, "Targeted delivery of chemotherapeutics: tumor-activated prodrug therapy," Advanced Drug Delivery Reviews, vol. 31, no. 1-2, pp. 89-104, 1998.

[137] M. P. Turunen, H. L. Puhakka, J. K. Koponen et al., "Peptide-retargeted adenovirus encoding a tissue inhibitor of metalloproteinase-1 decreases restenosis after intravascular gene transfer," Molecular Therapy, vol. 6, no. 3, pp. 306-312, 2002.

[138] T. T. Rissanen and S. Ylä-Herttuala, "Current status of cardiovascular gene therapy," Molecular Therapy, vol. 15, no. 7, pp. 1233-1247, 2007.
[139] H. E. von der Leyen, A. Mugge, C. Hanefeld et al., "A prospective, single-blind, multicenter, dose escalation study of intracoronary iNOS lipoplex (CAR-MP583) gene therapy for the prevention of restenosis in patients with de novo or restenotic coronary artery lesion (REGENT I extension)," Human Gene Therapy, vol. 22, no. 8, pp. 951-958, 2011.

[140] S. Yla-Herttuala, "In vivo and ex vivo strategies for vascular gene therapy," Journal of Submicroscopic Cytology and Pathology, vol. 32, p. 481, 2000.

[141] J. Rutanen, J. Markkanen, and S. Ylä-Herttuala, "Gene therapy for restenosis current status," Drugs, vol. 62, no. 11, pp. 1575-1585, 2002.

[142] S. Banai, M. Chorny, S. D. Gertz et al., "Locally delivered nanoencapsulated tyrphostin (AGL-2043) reduces neointima formation in balloon-injured rat carotid and stented porcine coronary arteries," Biomaterials, vol. 26, no. 4, pp. 451-461, 2005.

[143] H. D. Danenberg, I. Fishbein, J. Gao et al., "Macrophage depletion by clodronate-containing liposomes reduces neointimal formation after balloon injury in rats and rabbits," Circulation, vol. 106, no. 5, pp. 599-605, 2002.

[144] H. D. Danenberg, G. Golomb, A. Groothuis et al., "Liposomal alendronate inhibits systemic innate immunity and reduces in-stent neointimal hyperplasia in rabbits," Circulation, vol. 108, no. 22, pp. 2798-2804, 2003.

[145] E. Afergan, M. Ben-David, H. Epstein et al., "Liposomal simvastatin attenuates neointimal hyperplasia in rats," The AAPS Journal, vol. 12, no. 2, pp. 181-187, 2010.

[146] B. C. Berk, J. B. Gordon, and R. W. Alexander, "Pharmacologic roles of heparin and glucocorticoids to prevent restenosis after coronary angioplasty," Journal of the American College of Cardiology, vol. 17, no. 6, pp. 111B-117B, 1991.

[147] M. S. Weinberg, "The hidden effects of antihypertensive and lipid-lowering agents on the prevention and regression of atherogenesis: new management strategies," Rhode Island Medicine, vol. 78, no. 3, pp. 78-81, 1995.

[148] M. Hamon, E. Lécluse, J. P. Monassier, G. Grollier, and J. C. Potier, "Pharmacological approaches to the prevention of restenosis after coronary angioplasty," Drugs and Aging, vol. 13, no. 4, pp. 291-301, 1998.

[149] P. J. Casterella and P. S. Teirstein, "Prevention of coronary restenosis," Cardiology in Review, vol. 7, no. 4, pp. 219-231, 1999.

[150] R. Rabbani and E. J. Topol, "Strategies to achieve coronary arterial plaque stabilization," Cardiovascular Research, vol. 41, no. 2, pp. 402-417, 1999.

[151] A. W. Chan, D. P. Chew, and A. M. Lincoff, "Update on pharmacology for restenosis," Current Interventional Cardiology Reports, vol. 3, no. 2, pp. 149-155, 2001.

[152] R. Voisard, U. Seitzer, R. Baur et al., "A prescreening system for potential antiproliferative agents-implications for local treatment strategies of postangioplasty restenosis," International Journal of Cardiology, vol. 51, no. 1, pp. 15-28, 1995.

[153] Y. K. Ahn, M. H. Jeong, J. W. Kim et al., "Preventive effects of the heparin-coated stent on restenosis in the porcine model," Catheterization and Cardiovascular Interventions, vol. 48, no. 3, pp. 324-330, 1999.

[154] S. G. Ellis, G. S. Roubin, J. Wilentz, J. S. Douglas, and S. B. King, "Effect of 18- to 24-hour heparin administration for prevention of restenosis after uncomplicated coronary angioplasty," American Heart Journal, vol. 117, no. 4, pp. 777782, 1989. 
[155] P. S. K. Paty, R. C. Darling, P. B. Kreienberg et al., "The use of low-dose heparin is safe in carotid endarterectomy and avoids the use of protamine sulfate," Cardiovascular Surgery, vol. 7, no. 1, pp. 39-43, 1999.

[156] D. A. Cox, P. G. Anderson, G. S. Roubin, C. Y. Chou, S. K. Agrawal, and J. B. Cavender, "Effect of local delivery of heparin and methotrexate on neointimal proliferation in stented porcine coronary arteries," Coronary Artery Disease, vol. 3, no. 3, pp. 237-248, 1992.

[157] Y. Matsumoto, H. Shimokawa, K. Morishige, Y. Eto, and A. Takeshita, "Reduction in neointimal formation with a stent coated with multiple layers of releasable heparin in porcine coronary arteries," Journal of Cardiovascular Pharmacology, vol. 39, no. 4, pp. 513-522, 2002.

[158] M. C. M. Vrolix, V. M. Legrand, J. H. C. Reiber et al., "Heparin-coated Wiktor stents in human coronary arteries (MENTOR Trial)," American Journal of Cardiology, vol. 86, no. 4, pp. 385-389, 2000.

[159] P. W. Serruys, B. van Hout, H. Bonnier et al., "Randomised comparison of implantation of heparin-coated stents with balloon angioplasty in selected patients with coronary artery disease (Benestent II)," The Lancet, vol. 352, no. 9129, pp. 673-681, 1998.

[160] J. Wöhrle, E. Al-Khayer, U. Grötzinger et al., "Comparison of the heparin coated vs the uncoated Jostent-no influence on restenosis or clinical outcome," European Heart Journal, vol. 22, no. 19, pp. 1808-1816, 2001.

[161] J. W. Currier, T. K. Pow, C. C. Haudenschild, A. C. Minihan, and D. P. Faxon, "Low molecular weight heparin (enoxaparin) reduces restenosis after iliac angioplasty in the hypercholesterolemic rabbit," Journal of the American College of Cardiology, vol. 17, no. 6, pp. 118B-125B, 1991.

[162] M. Oberhoff, C. Herdeg, A. Baumbach et al., "Time course of smooth muscle cell proliferation after local drug delivery of low-molecular-weight heparin using a porous balloon catheter," Catheterization and Cardiovascular Diagnosis, vol. 41, pp. 268-274, 1997.

[163] M. Oberhoff, S. Novak, C. Herdeg et al., "Local and systemic delivery of low molecular weight heparin stimulates the reendothelialization after balloon angioplasty," Cardiovascular Research, vol. 38, no. 3, pp. 751-762, 1998.

[164] N. Meneveau, F. Schiele, G. Grollier et al., "Local delivery of nadroparin for the prevention of neointimal hyperplasia following stent implantation: results of the IMPRESS trial. A multicentre, randomized, clinical, angiographic and intravascular ultrasound study," European Heart Journal, vol. 21, no. 21, pp. 1767-1775, 2000.

[165] Z. Gu, B. E. Rolfe, Z. P. Xu, A. C. Thomas, J. H. Campbell, and G. Q. M. Lu, "Enhanced effects of low molecular weight heparin intercalated with layered double hydroxide nanoparticles on rat vascular smooth muscle cells," Biomaterials, vol. 31, no. 20, pp. 5455-5462, 2010.

[166] Z. Gu, B. E. Rolfe, A. C. Thomas, J. H. Campbell, G. Q. M. $\mathrm{Lu}$, and Z. P. Xu, "Cellular trafficking of low molecular weight heparin incorporated in layered double hydroxide nanoparticles in rat vascular smooth muscle cells," Biomaterials, vol. 32, no. 29, pp. 7234-7240, 2011.

[167] M. Heras, J. H. Chesebro, W. J. Penny, K. R. Bailey, L. Badimon, and V. Fuster, "Effects of thrombin inhibition on the development of acute platelet-thrombus deposition during angioplasty in pigs. Heparin versus recombinant hirudin, a specific thrombin inhibitor," Circulation, vol. 79, no. 3, pp. 657-665, 1989.
[168] C. Gerdes, V. Faber-Steinfeld, O. Yalkinoglu, and S. Wohlfeil, "Comparison of the effects of the thrombin inhibitor $r$ hirudin in four animal models of neointima formation after arterial injury," Arteriosclerosis, Thrombosis, and Vascular Biology, vol. 16, no. 10, pp. 1306-1311, 1996.

[169] M. Ragosta, W. L. Barry, L. W. Gimple et al., "Effect of thrombin inhibition with desulfatohirudin on early kinetics of cellular proliferation after balloon angioplasty in atherosclerotic rabbits," Circulation, vol. 93, no. 6, pp. 11941200, 1996.

[170] S. D. Gertz, J. T. Fallon, R. Gallo et al., "Hirudin reduces tissue factor expression in neointima after balloon injury in rabbit femoral and porcine coronary arteries," Circulation, vol. 98, no. 6, pp. 580-587, 1998.

[171] E. Alt, I. Haehnel, C. Beilharz et al., "Inhibition of neointima formation after experimental coronary artery stenting: a new biodegradable stent coating releasing hirudin and the prostacyclin analogue iloprost," Circulation, vol. 101, no. 12, pp. 1453-1458, 2000.

[172] P. A. Lapchak and D. M. Araujo, "Reducing bleeding complications after thrombolytic therapy for stroke: clinical potential of metalloproteinase inhibitors and spin trap agents," CNS Drugs, vol. 15, no. 11, pp. 819-829, 2001.

[173] S. Bjorkerud, "Impaired fibrinolysis-inducing capacity for postinjury phenotype of cultivated human arterial and human atherosclerotic intimal smooth muscle cells," Circulation Research, vol. 62, no. 5, pp. 1011-1018, 1988.

[174] T. Padro, J. J. Emeis, M. Steins, K. W. Schmid, and J. Kienast, "Quantification of plasminogen activators and their inhibitors in the aortic vessel wall in relation to the presence and severity of atherosclerotic disease," Arteriosclerosis, Thrombosis, and Vascular Biology, vol. 15, no. 7, pp. 893-902, 1995.

[175] P. Glas-Greenwalt, B. C. Dalton, and T. Astrup, "Localization of tissue plasminogen activator in relation to morphologic changes in human saphenous veins used as coronary artery bypass autografts," Annals of Surgery, vol. 181, no. 4, pp. 431441, 1975.

[176] P. Kauhanen, V. Sirén, O. Carpén, A. Vaheri, M. Lepäntalo, and R. Lassila, "Plasminogen activator inhibitor-1 neointima of vein grafts: its role in reduced fibrinolytic potential and graft failure," Circulation, vol. 96, no. 6, pp. 1783-1789, 1997.

[177] J. V. Manchio, J. Gu, L. Romar et al., "Disruption of graft endothelium correlates with early failure after off-pump coronary artery bypass surgery," Annals of Thoracic Surgery, vol. 79, no. 6, pp. 1991-1998, 2005.

[178] P. R. Hilfiker, J. M. Waugh, J. J. Li-Hawkins et al., "Enhancement of neointima formation with tissue-type plasminogen activator," Journal of Vascular Surgery, vol. 33, no. 4, pp. 821828, 2001.

[179] E. J. Topol, T. V. Byzova, and E. F. Plow, "Platelet GPIIb-IIIa blockers," The Lancet, vol. 353, no. 9148, pp. 227-231, 1999.

[180] S. A. Mousa, R. Kapil, and D. X. Mu, "Intravenous and oral antithrombotic efficacy of the novel platelet GPIIb/IIIa antagonist roxifiban (DMP754) and its free acid form, XV459," Arteriosclerosis, Thrombosis, and Vascular Biology, vol. 19, no. 10, pp. 2535-2541, 1999.

[181] W. Volker and V. Faber, "Aspirin reduces the growth of medial and neointimal thickenings in balloon-injured rat carotid arteries," Stroke, vol. 21, no. 12, pp. IV44-IV45, 1990.

[182] A. J. Coukell and A. Markham, "Clopidogrel," Drugs, vol. 54, no. 5, pp. 745-750, 1997. 
[183] A. Schömig, F. J. Neumann, A. Kastrati et al., "A randomized comparison of antiplatelet and anticoagulant therapy after the placement of coronary-artery stents," The New England Journal of Medicine, vol. 334, no. 17, pp. 1084-1089, 1996.

[184] B. S. Coller, "The role of platelets in arterial thrombosis and the rationale for blockade of platelet GPIIb/IIIa receptors as antithrombotic therapy," European Heart Journal, vol. 16, pp. L11-L15, 1995.

[185] R. R. Azar, R. G. McKay, P. D. Thompson et al., "Abciximab in primary coronary angioplasty for acute myocardial infarction improves short- and medium-term outcomes," Journal of the American College of Cardiology, vol. 32, no. 7, pp. 19962002, 1998.

[186] D. Hasdai, C. S. Rihal, M. R. Bell et al., "Abciximab administration and outcome after intracoronary stent implantation," American Journal of Cardiology, vol. 82, no. 6, pp. 705-709, 1998.

[187] G. W. Barsness, C. Buller, E. M. Ohman et al., "Reduced thrombus burden with abciximab delivered locally before percutaneous intervention in saphenous vein grafts," American Heart Journal, vol. 139, no. 5, pp. 824-829, 2000.

[188] Y. J. Hong, M. H. Jeong, S. R. Lee et al., "Anti-inflammatory effect of abciximab-coated stent in a porcine coronary restenosis model," Journal of Korean Medical Science, vol. 22, no. 5, pp. 802-809, 2007.

[189] A. J. Marcus, L. B. Safier, M. J. Broekman et al., "Thrombosis and inflammation as multicellular processes: significance of cell-cell interactions," Thrombosis and Haemostasis, vol. 74, no. 1, pp. 213-217, 1995.

[190] C. Timmermans, M. Vrolix, J. Vanhaecke et al., "Ridogrel in the setting of percutaneous transluminal coronary angioplasty," American Journal of Cardiology, vol. 68, no. 5, pp. 463-466, 1991.

[191] Y. Yabe, K. Okamoto, H. Oosawa et al., "Does a thromboxane A2 synthetase inhibitor prevent restenosis after PTCA?" Circulation, vol. 80, no. 4, p. II260, 1989.

[192] J. T. Willerson, S. K. Yao, J. McNatt et al., "Frequency and severity of cyclic flow alternations and platelet aggregation predict the severity of neointimal proliferation following experimental coronary stenosis and endothelial injury," Proceedings of the National Academy of Sciences of the United States of America, vol. 88, no. 23, pp. 10624-10628, 1991.

[193] H. V. Anderson, J. McNatt, F. J. Clubb et al., "Platelet inhibition reduces cyclic flow variations and neointimal proliferation in normal and hypercholesterolemic-atherosclerotic canine coronary arteries," Circulation, vol. 104, no. 19, pp. 2331-2337, 2001.

[194] J. M. van Lierde, M. C. Vrolix, I. K. de Scheerer et al., "Feasibility of transient delivery of ridogrel via microporous balloon technique in normal canine arteries," Circulation, vol. 84, p. II296, 1991.

[195] Y. Numaguchi, K. Okumura, M. Harada et al., "Catheterbased prostacyclin synthase gene transfer prevents in-stent restenosis in rabbit atheromatous arteries," Cardiovascular Research, vol. 61, no. 1, pp. 177-185, 2004.

[196] N. Kohda, T. Tani, S. Nakayama et al., "Effect of cilostazol, a phosphodiesterase III inhibitor, on experimental thrombosis in the porcine carotid artery," Thrombosis Research, vol. 96, no. 4, pp. 261-268, 1999.

[197] E. Tsuchikane, T. Suzuki, O. Katoh, and T. Suzuki, "Examination of anti-intima hyperplastic effect on cilostazol-eluting stent in a porcine model," Journal of Invasive Cardiology, vol. 19, no. 3, pp. 109-112, 2007.
[198] S. Take, M. Matsutani, H. Ueda et al., "Effect of cilostazol in preventing restenosis after percutaneous transluminal coronary angioplasty," American Journal of Cardiology, vol. 79, no. 8, pp. 1097-1099, 1997.

[199] K. Kozuma, K. Hara, M. Yamasaki et al., "Effects of cilostazol on late lumen loss and repeat revascularization after PalmazSchatz coronary stent implantation," American Heart Journal, vol. 141, no. 1, pp. 124-130, 2001.

[200] M. Sekiya, J. Funada, K. Watanabe, M. Miyagawa, and H. Akutsu, "Effects of probucol and cilostazol alone and in combination on frequency of poststenting restenosis," American Journal of Cardiology, vol. 82, no. 2, pp. 144-147, 1998.

[201] N. Ishizaka, J. Taguchi, Y. Kimura et al., "Effects of a single local administration of cilostazol on neointimal formation in balloon-injured rat carotid artery," Atherosclerosis, vol. 142, no. 1, pp. 41-46, 1999.

[202] G. A. Higgs, K. G. Mugridge, S. Moncada, and J. R. Vane, "Inhibition of tissue damage by the arachidonate lipoxygenase inhibitor BW755C," Proceedings of the National Academy of Sciences of the United States of America, vol. 81, no. 9, pp. 2890-2892, 1984.

[203] I. de Meyer, W. Martinet, D. M. Schrijvers et al., "Toll-like receptor 7 stimulation by imiquimod induces macrophage autophagy and inflammation in atherosclerotic plaques," Basic Research in Cardiology, vol. 107, p. 269, 2012.

[204] A. E. Villa, L. A. Guzman, W. Chen, G. Golomb, R. J. Levy, and E. J. Topol, "Local delivery of dexamethasone for prevention of neointimal proliferation in a rat model of balloon angioplasty," The Journal of Clinical Investigation, vol. 93, no. 3, pp. 1243-1249, 1994.

[205] T. Suzuki, G. Kopia, S. I. Hayashi et al., "Stent-based delivery of sirolimus reduces neointimal formation in a porcine coronary model," Circulation, vol. 104, no. 10, pp. 11881193, 2001.

[206] A. König, M. Leibig, J. Rieber et al., "Randomized comparison of dexamethasone-eluting stents with bare metal stent implantation in patients with acute coronary syndrome: serial angiographic and sonographic analysis," American Heart Journal, vol. 153, no. 6, pp. 979.e1-979.e8, 2007.

[207] H. Epstein, V. Berger, I. Levi et al., "Nanosuspensions of alendronate with gallium or gadolinium attenuate neointimal hyperplasia in rats," Journal of Controlled Release, vol. 117, no. 3, pp. 322-332, 2007.

[208] H. Kusama, S. Kikuchi, S. Tazawa et al., "Tranilast inhibits the proliferation of human coronary smooth muscle cell through the activation of p21 waf 1 ," Atherosclerosis, vol. 143, no. 2, pp. 307-313, 1999.

[209] A. Saiura, M. Sata, Y. Hirata, R. Nagai, and M. Makuuchi, "Tranilast inhibits transplant-associated coronary arteriosclerosis in a murine model of cardiac transplantation," European Journal of Pharmacology, vol. 433, no. 2-3, pp. 163$168,2001$.

[210] M. R. Ward, A. Agrotis, P. Kanellakis, J. Hall, G. Jennings, and A. Bobik, "Tranilast prevents activation of transforming growth factor- $\beta$ system, leukocyte accumulation, and neointimal growth in porcine coronary arteries after stenting," Arteriosclerosis, Thrombosis, and Vascular Biology, vol. 22, no. 6, pp. 940-948, 2002.

[211] K. Kosuga, H. Tamai, K. Ueda et al., "Effectiveness of tranilast on restenosis after directional coronary atherectomy," American Heart Journal, vol. 134, no. 4, pp. 712-718, 1997. 
[212] L. Denes, L. Entz, and V. Jancsik, "Restenosis and therapy," International Journal of Vascular Medicine, vol. 2012, Article ID 406236, 9 pages, 2012.

[213] J. Saltis, A. C. Thomas, A. Agrotis, J. H. Campbell, G. R. Campbell, and A. Bobik, "Expression of growth factor receptors on arterial smooth muscle cells. Dependency on cell phenotype and serum factors," Atherosclerosis, vol. 118, no. 1, pp. 77-87, 1995.

[214] H. Matsuno, J. M. Stassen, M. F. Hoylaerts, J. Vermylen, and H. Deckmyn, "Fast and reproducible vascular neointima formation in the hamster carotid artery: effects of trapidil and captopril," Thrombosis and Haemostasis, vol. 74, no. 6, pp. 1591-1596, 1995.

[215] M. W. Liu, G. S. Roubin, K. A. Robinson et al., "Trapidil in preventing restenosis after balloon angioplasty in the atherosclerotic rabbit," Circulation, vol. 81, no. 3, pp. 10891093, 1990.

[216] K. Zacharowski, D. Schneidmüller, W. Ibe et al., "Effects of local delivery of trapidil on neointima formation in a rabbit angioplasty model," British Journal of Pharmacology, vol. 129, no. 3, pp. 566-572, 2000.

[217] S. Okamoto, M. Inden, M. Setsuda, T. Konishi, and T. Nakano, "Effects of trapidil (triazolopyrimidine), a plateletderived growth factor antagonist, in preventing stenosis after percutaneous transluminal coronary angioplasty," American Heart Journal, vol. 123, no. 6, pp. 1439-1444, 1992.

[218] D. X. Sun, Z. Liu, X. D. Tan et al., "Nanoparticle-mediated local delivery of an antisense TGF $\beta 1$ construct inhibits intimal hyperplasia in autogenous vein grafts in rats," PLoS ONE, vol. 7, no. 7, Article ID e41857, 2012.

[219] E. Stringa, V. Knäuper, G. Murphy, and J. Gavrilovic, "Collagen degradation and platelet-derived growth factor stimulate the migration of vascular smooth muscle cells," Journal of Cell Science, vol. 113, no. 11, pp. 2055-2064, 2000.

[220] I. Fishbein, J. Waltenberger, S. Banai et al., "Local delivery of platelet-derived growth factor receptor-specific tyrphostin inhibits neointimal formation in rats," Arteriosclerosis, Thrombosis, and Vascular Biology, vol. 20, no. 3, pp. 667676, 2000.

[221] S. Banai, S. D. Gertz, L. Gavish et al., "Tyrphostin AGL2043 eluting stent reduces neointima formation in porcine coronary arteries," Cardiovascular Research, vol. 64, no. 1, pp. 165-171, 2004.

[222] E. D. Santoian, J. E. Schneider, M. B. Gravanis et al., "Angiopeptin inhibits intimal hyperplasia after angioplasty in porcine coronary arteries," Circulation, vol. 88, no. 1, pp. 11$14,1993$.

[223] O. H. Kwok, W. H. Chow, T. C. Law et al., "First human experience with angiopeptin-eluting stent: a quantitative coronary angiography and three-dimensional intravascular ultrasound study," Catheterization and Cardiovascular Interventions, vol. 66, no. 4, pp. 541-546, 2005.

[224] J. Taguchi, J. Abe, H. Okazaki et al., "Angiotensin converting enzyme inhibitors or DuP753 prevent neointimal formation following balloon injury with single topical or multiple systemic application," Biochemical and Biophysical Research Communications, vol. 196, no. 2, pp. 969-974, 1993.

[225] M. Pretorius, L. J. Murphey, J. A. McFarlane, D. E. Vaughan, and N. J. Brown, "Angiotensin-converting enzyme inhibition alters the fibrinolytic response to cardiopulmonary bypass," Circulation, vol. 108, no. 25, pp. 3079-3083, 2003.

[226] N. Beohar, J. D. Flaherty, C. J. Davidson et al., "Antirestenotic effects of a locally delivered caspase inhibitor in a balloon injury model," Circulation, vol. 109, no. 1, pp. 108-113, 2004.
[227] T. N. Wight, "The extracellular matrix and atherosclerosis," Current Opinion in Lipidology, vol. 6, no. 5, pp. 326-334, 1995.

[228] J. L. Johnson, L. Devel, B. Czarny et al., "A selective matrix metalloproteinase-12 inhibitor retards atherosclerotic plaque development in apolipoprotein E-knockout mice," Arteriosclerosis, Thrombosis, and Vascular Biology, vol. 31, no. 3, pp. 528-535, 2011.

[229] D. W. M. Muller, S. G. Ellis, and E. J. Topol, "Colchicine and antineoplastic therapy for the prevention of restenosis after percutaneous coronary interventions," Journal of the American College of Cardiology, vol. 17, no. 6, pp. 126B-131B, 1991.

[230] D. Baruch, B. Bahnak, J. P. Girma, and D. Meyer, "Von Willebrand factor and platelet function," Bailliere's Clinical Haematology, vol. 2, no. 3, pp. 627-672, 1989.

[231] D. P. Faxon and J. W. Currier, "Prevention of post-PTCA restenosis," Annals of the New York Academy of Sciences, vol. 748, pp. 419-428, 1995.

[232] I. Gradus-Pizlo, R. L. Wilensky, K. L. March et al., "Local delivery of biodegradable microparticles containing colchicine or a colchicine analogue: effects on restenosis and implications for catheter-based drug delivery," Journal of the American College of Cardiology, vol. 26, no. 6, pp. 1549-1557, 1995.

[233] C. Herdeg, M. Oberhoff, and K. R. Karsch, "Antiproliferative stent coatings: taxol and related compounds," Seminars in Interventional Cardiology, vol. 3, no. 3-4, pp. 197-199, 1998.

[234] C. W. Hwang, D. Wu, and E. R. Edelman, "Physiological transport forces govern drug distribution for stent-based delivery," Circulation, vol. 104, no. 5, pp. 600-605, 2001.

[235] D. E. Drachman, E. R. Edelman, P. Seifert et al., "Neointimal thickening after stent delivery of paclitaxel: change in composition and arrest of growth over six months," Journal of the American College of Cardiology, vol. 36, no. 7, pp. 2325-2332, 2000.

[236] A. Farb, P. F. Heller, S. Shroff et al., "Pathological analysis of local delivery of paclitaxel via a polymer-coated stent," Circulation, vol. 104, no. 4, pp. 473-479, 2001.

[237] P. E. Signore, L. S. Machan, J. K. Jackson et al., "Complete inhibition of intimal hyperplasia by perivascular delivery of paclitaxel in balloon-injured rat carotid arteries," Journal of Vascular and Interventional Radiology, vol. 12, no. 1, pp. 7988, 2001.

[238] B. Kelly, M. Melhem, J. Zhang et al., "Perivascular paclitaxel wraps block arteriovenous graft stenosis in a pig model," Nephrology Dialysis Transplantation, vol. 21, no. 9, pp. 24252431, 2006.

[239] J. M. Chan, L. Zhang, R. Tong et al., "Spatiotemporal controlled delivery of nanoparticles to injured vasculature," Proceedings of the National Academy of Sciences of the United States of America, vol. 107, no. 5, pp. 2213-2218, 2010.

[240] F. Liistro, G. Stankovic, C. Di Mario et al., "First clinical experience with a paclitaxel derivate-eluting polymer stent system implantation for in-stent restenosis: immediate and long-term clinical and angiographic outcome," Circulation, vol. 105, no. 16, pp. 1883-1886, 2002.

[241] K. Tanabe, P. W. Serruys, E. Grube et al., "TAXUS III trial: instent restenosis treated with stent-based delivery of paclitaxel incorporated in a slow-release polymer formulation," Circulation, vol. 107, no. 4, pp. 559-564, 2003.

[242] O. A. Mendiz, W. H. Ahmed, C. M. Fava et al., "Clinical outcome after saphenous vein stenting with Taxus Liberte 
Stent: results from the OLYMPIA registry (TAXUS Liberte Postapproval Global Program)," Angiology, vol. 63, no. 8, pp. 574-578, 2012.

[243] S. H. Duda, T. C. Poerner, B. Wiesinger et al., "Drug-eluting stents: potential applications for peripheral arterial occlusive disease," Journal of Vascular and Interventional Radiology, vol. 14, no. 3, pp. 291-301, 2003.

[244] I. Iakovou, T. Schmidt, E. Bonizzoni et al., "Incidence, predictors and outcome of thrombosis after succesful implantation of drug-eluting stents," Journal of the American Medical Association, vol. 293, no. 17, pp. 2126-2130, 2005.

[245] M. Joner, A. V. Finn, A. Farb et al., "Pathology of drug-eluting stents in humans-delayed healing and late thrombotic risk," Journal of the American College of Cardiology, vol. 48, no. 1, pp. 193-202, 2006.

[246] M. Poon, S. O. Marx, R. Gallo, J. J. Badimon, M. B. Taubman, and A. R. Marks, "Rapamycin inhibits vascular smooth muscle cell migration," The Journal of Clinical Investigation, vol. 98, no. 10, pp. 2277-2283, 1996.

[247] P. J. Mohacsi, D. Tuller, B. Hulliger, and P. L. J. Wijngaard, "Different inhibitory effects of immunosuppressive drugs on human and rat aortic smooth muscle and endothelial cell proliferation stimulated by platelet-derived growth factor or endothelial cell growth factor," Journal of Heart and Lung Transplantation, vol. 16, no. 5, pp. 484-492, 1997.

[248] S. N. Sehgal, "Rapamune (RAPA, rapamycin, sirolimus): mechanism of action immunosuppressive effect results from blockade of signal transduction and inhibition of cell cycle progression," Clinical Biochemistry, vol. 31, no. 5, pp. 335340, 1998.

[249] C. R. Gregory, P. Huie, M. E. Billingham, and R. E. Morris, "Rapamycin inhibits arterial intimal thickening caused by both alloimmune and mechanical injury. Its effect on cellular, growth factor, and cytokine responses in injured vessels," Transplantation, vol. 55, no. 6, pp. 1409-1418, 1993.

[250] G. J. Murphy and M. L. Nicholson, "Rapamycin has no effect on fibrosis-associated gene expression or extracellular matrix accumulation when administered to animals with established or early allograft vasculopathy," The Journal of Thoracic and Cardiovascular Surgery, vol. 126, no. 6, pp. 2058-2064, 2003.

[251] S. E. Burke, N. L. Lubbers, Y. W. Chen et al., "Neointimal formation after balloon-induced vascular injury in Yucatan minipigs is reduced by oral rapamycin," Journal of Cardiovascular Pharmacology, vol. 33, no. 6, pp. 829-835, 1999.

[252] B. D. Klugherz, G. Llanos, W. Lieuallen et al., "Twenty-eightday efficacy and phamacokinetics of the sirolimus-eluting stent," Coronary Artery Disease, vol. 13, no. 3, pp. 183-188, 2002.

[253] H. L. Chen, K. Liu, X. Y. Meng, X. D. Wen, and Q. S. You, "Local application of rapamycin inhibits vein graft restenosis in rabbits," Transplantation Proceedings, vol. 43, no. 5, pp. 2017-2021, 2011.

[254] T. Schachner, Y. Zou, A. Oberhuber et al., "Local application of rapamycin inhibits neointimal hyperplasia in experimental vein grafts," Annals of Thoracic Surgery, vol. 77, no. 5, pp. 1580-1585, 2004.

[255] J. A. S. Muldowney, J. R. Stringham, S. E. Levy et al., "Antiproliferative agents alter vascular plasminogen activator inhibitor-1 expression: a potential prothrombotic mechanism of drug-eluting stents," Arteriosclerosis, Thrombosis, and Vascular Biology, vol. 27, no. 2, pp. 400-406, 2007.

[256] O. Massoud and R. H. Wiesner, "The use of sirolimus should be restricted in liver transplantation," Journal of Hepatology, vol. 56, no. 1, pp. 288-290, 2012.
[257] R. Virmani, G. Guagliumi, A. Farb et al., "Localized hypersensitivity and late coronary thrombosis secondary to a sirolimus-eluting stent: should we be cautious?" Circulation, vol. 109, no. 6, pp. 701-705, 2004.

[258] P. Vermeersch, P. Agostoni, S. Verheye et al., "Increased late mortality after sirolimus-eluting stents versus bare-metal stents in diseased saphenous vein grafts: results from the randomized DELAYED RRISC Trial," Journal of the American College of Cardiology, vol. 50, no. 3, pp. 261-267, 2007.

[259] M. Igarashi, Y. Takeda, S. Mori et al., "Suppression of neointimal thickening by a newly developed HMG-CoA reductase inhibitor, BAYw6228, and its inhibitory effect on vascular smooth muscle cell growth," British Journal of Pharmacology, vol. 120, no. 6, pp. 1172-1178, 1997.

[260] M. R. Soma, E. Donetti, C. Parolini et al., "HMG CoA reductase inhibitors. In vivo effects on carotid intimal thickening in normocholesterolemic rabbits," Arteriosclerosis and Thrombosis, vol. 13, no. 4, pp. 571-578, 1993.

[261] J. Alfon, J. F. Guasch, M. Berrozpe, and L. Badimon, "Nitric oxide synthase II (NOS II) gene expression correlates with atherosclerotic intimal thickening. Preventive effects of HMG-CoA reductase inhibitors," Atherosclerosis, vol. 145, no. 2, pp. 325-331, 1999.

[262] J. R. Sindermann, L. Fan, K. A. Weigel et al., "Differences in the effects of HMG-CoA reductase inhibitors on proliferation and viability of smooth muscle cells in culture," Atherosclerosis, vol. 150, no. 2, pp. 331-341, 2000.

[263] Z. Luan, A. J. Chase, and A. C. Newby, "Statins inhibit secretion of metalloproteinases-1, $-2,-3$, and -9 from vascular smooth muscle cells and macrophages," Arteriosclerosis, Thrombosis, and Vascular Biology, vol. 23, no. 5, pp. 769-775, 2003.

[264] P. Libby and M. Aikawa, "Effects of statins in reducing thrombotic risk and modulating plaque vulnerability," Clinical Cardiology, vol. 26, no. 1, pp. I11-I14, 2003.

[265] A. Yilmaz, C. Reiss, O. Tantawi et al., "HMG-CoA reductase inhibitors suppress maturation of human dendritic cells: new implications for atherosclerosis," Atherosclerosis, vol. 172, no. 1, pp. 85-93, 2004.

[266] T. A. Miettinen, K. Pyörälä, A. G. Olsson et al., "Cholesterollowering therapy in women and elderly patients with myocardial infarction or angina pectoris: findings from the Scandinavian Simvastatin Survival Study (4S)," Circulation, vol. 96, no. 12, pp. 4211-4218, 1997.

[267] The Long-Term Intervention with Pravastatin in Ischaemic Disease (LIPID) Study Group, "Prevention of cardiovascular events and death with pravastatin in patients with coronary heart disease and a broad range of initial cholesterol levels," The New England Journal of Medicine, vol. 339, pp. 13491357, 1998.

[268] B. Cucchiara and S. E. Kasner, "Use of statins in CNS disorders," Journal of the Neurological Sciences, vol. 187, no. 1-2, pp. 81-89, 2001.

[269] W. S. Weintraub, S. J. Boccuzzi, J. L. Klein et al., "Lack of effect of lovastatin on restenosis after coronary angioplasty," The New England Journal of Medicine, vol. 331, no. 20, pp. 1331-1337, 1994.

[270] M. E. Bertrand, E. P. McFadden, J. C. Fruchart et al., "Effect of pravastatin on angiographic restenosis after coronary balloon angioplasty," Journal of the American College of Cardiology, vol. 30, no. 4, pp. 863-869, 1997.

[271] A. Kleemann, S. Eckert, A. von Eckardstein et al., "Effects of lovastatin on progression of non-dilated and dilated coronary segments and on restenosis in patients after PTCA. The 
cholesterol lowering atherosclerosis PTCA trial (CLAPT)," European Heart Journal, vol. 20, no. 19, pp. 1393-1406, 1999.

[272] D. H. Walter, V. Schächinger, M. Elsner, S. Mach, W. Auch-Schwelk, and A. M. Zeiher, "Effect of statin therapy on restenosis after coronary stent implantation," American Journal of Cardiology, vol. 85, no. 8, pp. 962-968, 2000.

[273] H. C. Jeong, Y. Ahn, Y. J. Hong et al., "Statin therapy to reduce stent thrombosis in acute myocardial infarction patients with elevated high-sensitivity C-reactiveprotein," International Journal of Cardiology. In press.

[274] K. Miyauchi, T. Kasai, T. Yokayama et al., "Effectiveness of statin-eluting stent on early inflammatory response and neointimal thickness in a porcine coronary model," Circulation Journal, vol. 72, no. 5, pp. 832-838, 2008.

[275] M. N. Diaz, B. Frei, J. A. Vita, and J. F. Keaney, "Antioxidants and atherosclerotic heart disease," The New England Journal of Medicine, vol. 337, no. 6, pp. 408-416, 1997.

[276] Heart Protection Study Collaborative Group, "MRC/BHF heart protection study of antioxidant vitamin supplementation in 20536 high-risk individuals: a randomised placebocontrolled trial," The Lancet, vol. 360, no. 9326, pp. 23-33, 2002.

[277] E. R. Edelman, "Vessel size, antioxidants, and restenosis: never too small, not too little, but often too late," Circulation, vol. 97, no. 5, pp. 416-420, 1998.

[278] J. C. Tardif, G. Côté, J. Lespérance et al., "Probucol and multivitamins in the prevention of restenosis after coronary angioplasty," The New England Journal of Medicine, vol. 337, no. 6, pp. 365-372, 1997.

[279] T. Kita, Y. Nagano, M. Yokode et al., "Probucol prevents the progression of atherosclerosis in Watanabe heritable hyperlipidemic rabbit, an animal model for familial hypercholesterolemia," Proceedings of the National Academy of Sciences of the United States of America, vol. 84, no. 16, pp. 5928-5931, 1987.

[280] G. Côté, J. C. Tardif, J. Lespérance et al., "Effects of probucol on vascular remodeling after coronary angioplasty," Circulation, vol. 99, no. 1, pp. 30-35, 1999.

[281] H. Yokoi, H. Daida, Y. Kuwabara et al., "Effectiveness of an antioxidant in preventing restenosis after percutaneous transluminal coronary angioplasty: the probucol angioplasty restenosis trial," Journal of the American College of Cardiology, vol. 30, no. 4, pp. 855-862, 1997.

[282] D. L. Tribble, "Antioxidant consumption and risk of coronary heart disease: emphasis on vitamin $\mathrm{C}$, vitamin $\mathrm{E}$, and $\beta$ carotene," Circulation, vol. 99, no. 4, pp. 591-595, 1999.

[283] J. J. Kleinedler, J. D. Foley, E. A. Orchard et al., "Novel nanocomposite stent coating releasing resveratrol and quercetin reduces neointimal hyperplasia and promotes reendothelialization," Journal of Controlled Release, vol. 159, no. 1, pp. 27-33, 2012.

[284] R. Ross, "The pathogenesis of atherosclerosis: a perspective for the 1990s," Nature, vol. 362, no. 6423, pp. 801-809, 1993.

[285] N. Shukla, G. D. Angelini, R. Ascione, S. Talpahewa, R. Capoun, and J. Y. Jeremy, "Nitric oxide donating aspirins: novel drugs for the treatment of saphenous vein graft failure," Annals of Thoracic Surgery, vol. 75, no. 5, pp. 1437-1442, 2003.

[286] K. Mavromatis, T. Fukai, M. Tate, N. Chesler, D. N. Ku, and Z. S. Galis, "Early effects of arterial hemodynamic conditions on human saphenous veins perfused ex vivo," Arteriosclerosis, Thrombosis, and Vascular Biology, vol. 20, no. 8, pp. 1889$1895,2000$.
[287] J. H. Bräsen, O. Leppänen, M. Inkala et al., "extracellular superoxide dismutase accelerates endothelial recovery and inhibits in-stent restenosis in stented atherosclerotic Watanabe heritable hyperlipidemic rabbit aorta," Journal of the American College of Cardiology, vol. 50, no. 23, pp. 22492253, 2007.

[288] D. Wiedemann, A. Kocher, N. Bonaros et al., "Perivascular administration of drugs and genes as a means of reducing vein graft failure," Current Opinion in Pharmacology, vol. 12, no. 2, pp. 203-216, 2012.

[289] E. Allaire and A. W. Clowes, "Endothelial cell injury in cardiovascular surgery: the intimal hyperplastic response," Annals of Thoracic Surgery, vol. 63, no. 2, pp. 582-591, 1997. 


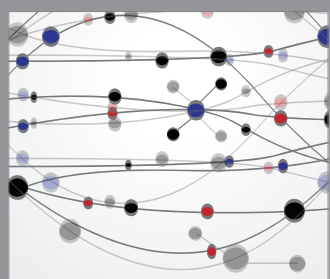

The Scientific World Journal
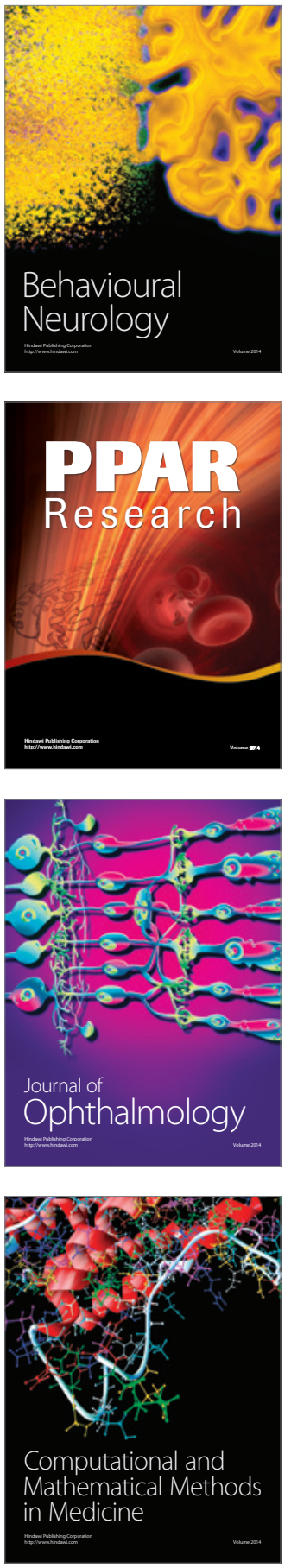

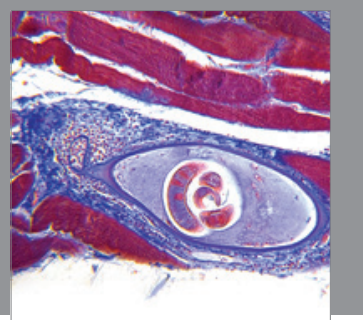

Gastroenterology

Research and Practice
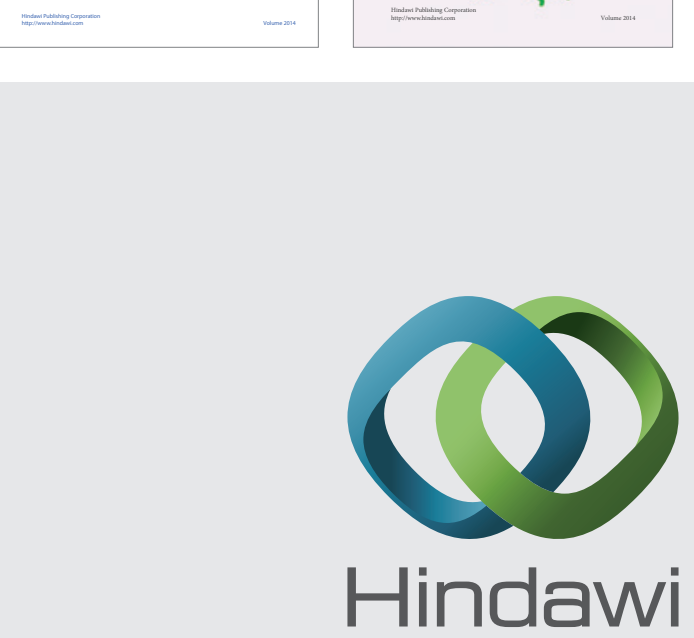

Submit your manuscripts at

http://www.hindawi.com
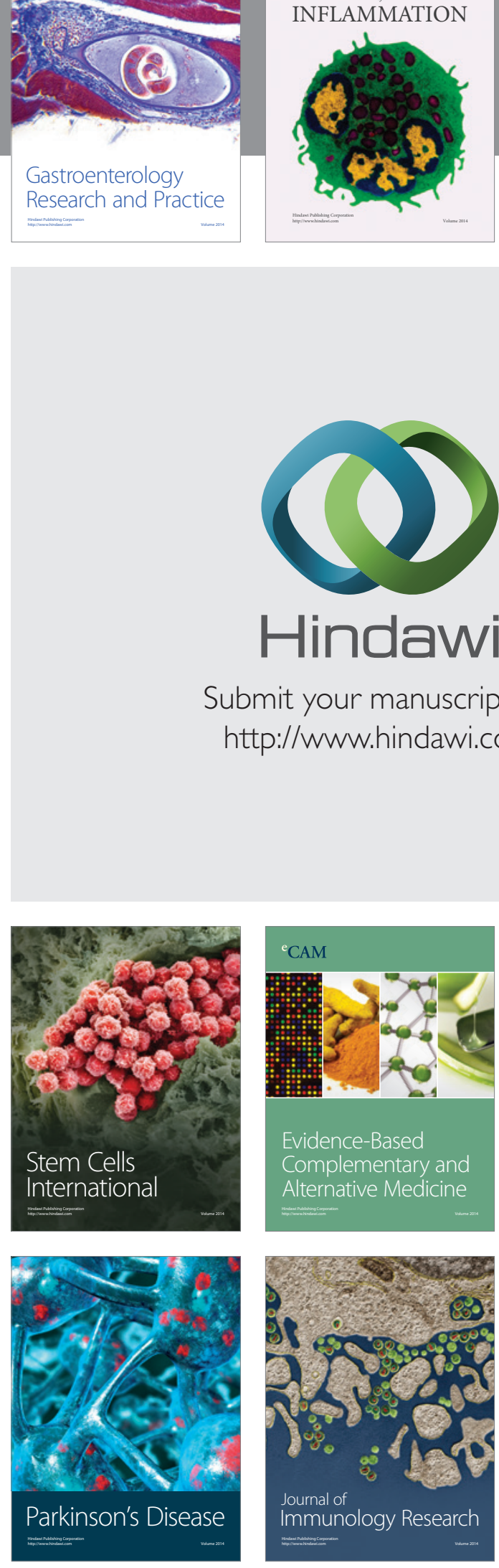

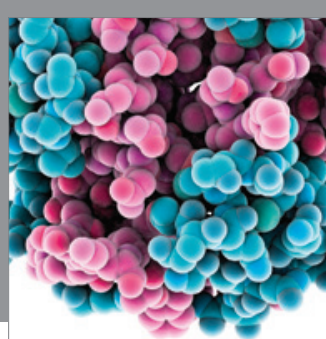

Diabetes Research
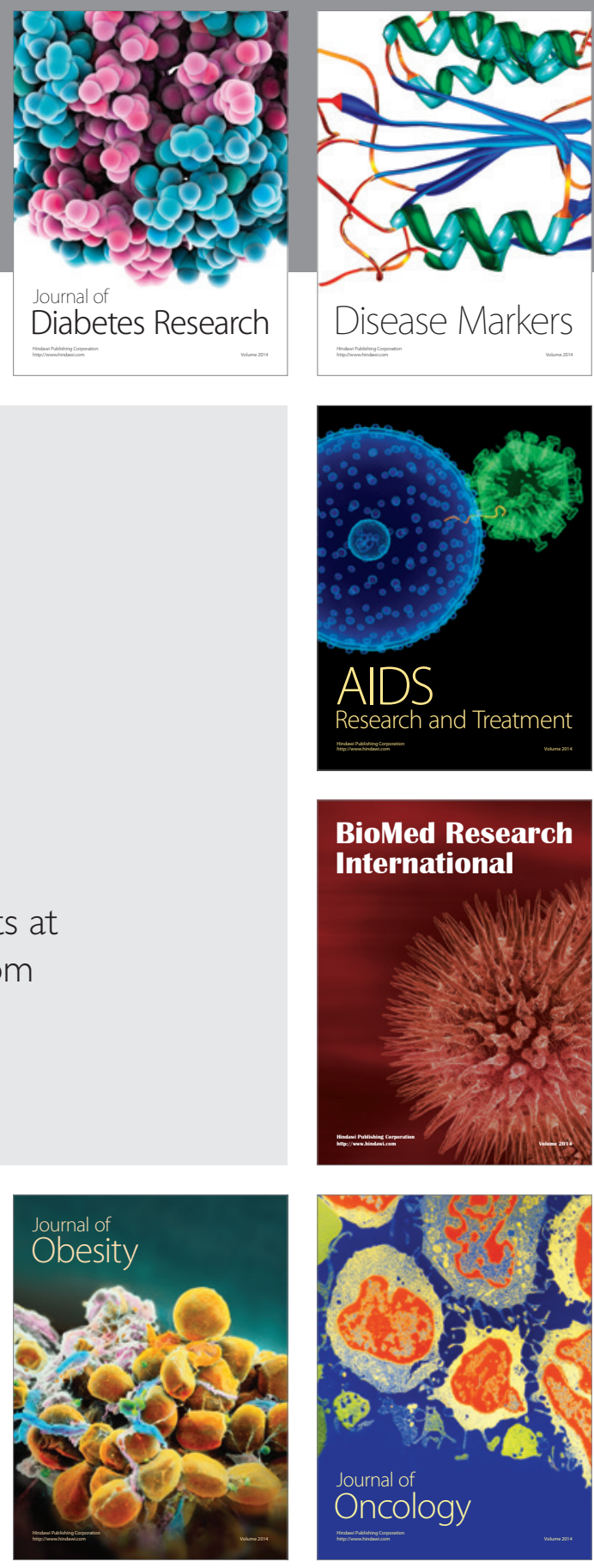

Disease Markers

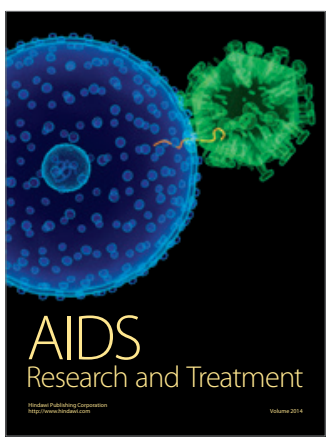

BioMed Research

International
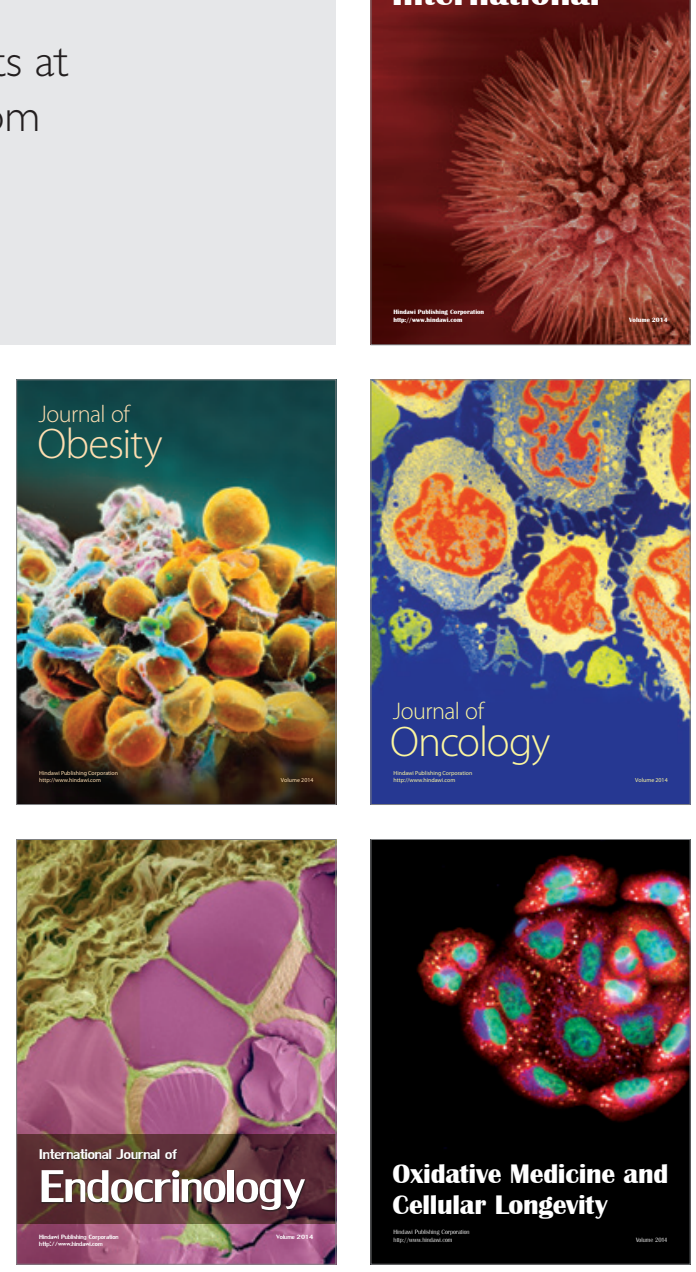